TITLE:

\title{
Microplasma thruster powered by X-band microwaves
}

\author{
AUTHOR(S): \\ Takahashi, Takeshi; Mori, Daisuke; Kawanabe, \\ Tetsuo; Takao, Yoshinori; Eriguchi, Koji; Ono, \\ Kouichi
}

\section{CITATION:}

Takahashi, Takeshi ...[et al]. Microplasma thruster powered by X-band microwaves. Journal of Applied Physics 2019, 125(8): 083301.

\section{ISSUE DATE:}

2019-02-28

URL:

http://hdl.handle.net/2433/236575

\section{RIGHT:}

The following article appeared in : Takahashi, T. et. al. Microplasma thruster powered by X-band microwaves. J. Appl. Phys. 125, 083301 (2019) and may be found at:

https://doi.org/10.1063/1.5054790.; The full-text file will be made open to the public on 28 February 2020 in accordance with publisher's 'Terms and Conditions for Self-Archiving'. 


\section{Microplasma thruster powered by X-band microwaves}

Cite as: J. Appl. Phys. 125, 083301 (2019); https://doi.org/10.1063/1.5054790

Submitted: 03 September 2018 . Accepted: 24 January 2019 . Published Online: 22 February 2019

Takeshi Takahashi, Daisuke Mori, Tetsuo Kawanabe, Yoshinori Takao (D), Koji Eriguchi, and Kouichi Ono
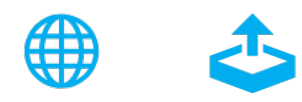

\section{ARTICLES YOU MAY BE INTERESTED IN}

High-voltage microdischarge as a source of extreme density plasma

Physics of Plasmas 25, 013509 (2018); https://doi.org/10.1063/1.5017594

Space micropropulsion systems for Cubesats and small satellites: From proximate targets to furthermost frontiers

Applied Physics Reviews 5, 011104 (2018); https://doi.org/10.1063/1.5007734

Non-invasive time-resolved measurements of anomalous collision frequency in a Hall thruster Physics of Plasmas 26, 013516 (2019); https://doi.org/10.1063/1.5077008

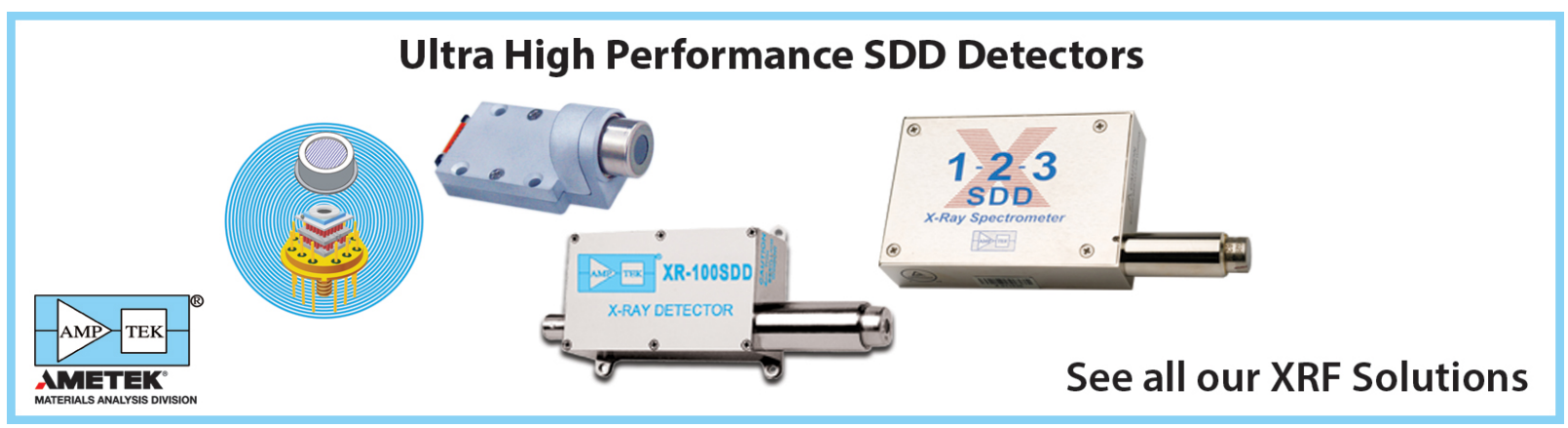




\title{
Microplasma thruster powered by X-band microwaves
}

\author{
Cite as: J. Appl. Phys. 125, 083301 (2019); doi: 10.1063/1.5054790 \\ Submitted: 3 September 2018 - Accepted: 24 January 2019 . \\ Published Online: 22 February 2019
}

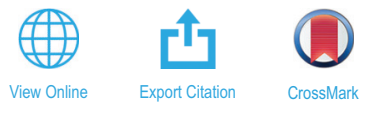

Takeshi Takahashi, ${ }^{1, a)}$ Daisuke Mori, ${ }^{1, b)}$ Tetsuo Kawanabe, ${ }^{1, c)}$ Yoshinori Takao, ${ }^{1, d)}$ (D) Koji Eriguchi, ${ }^{1}$ and Kouichi Ono ${ }^{1,2, e)}$

\author{
AFFILIATIONS \\ ${ }^{1}$ Department of Aeronautics and Astronautics, Graduate School of Engineering, Kyoto University, Kyoto-daigaku Katsura, \\ Nishikyo-ku, Kyoto 615-8540, Japan \\ 2Joining and Welding Research Institute, Osaka University, 11-1 Mihogaoka, Ibaraki, Osaka 567-0047, Japan \\ a) Present address: Sigma Corporation, Kawasaki, Kanagawa 215-8530, Japan \\ b) Present address: Mitsubishi Heavy Industries, Ltd., Nagoya Aerospace Systems Works, Nagoya, Aichi 455-8515, Japan. \\ ${ }^{c}$ Present address: Hitachi Ltd., Central Research Laboratory, Kokubunji, Tokyo 185-8601, Japan. \\ ${ }^{d)}$ Present address: Division of Systems Research, Faculty of Engineering, Yokohama National University, Yokohama, Kanagawa \\ 240-8501, Japan. \\ e)Electronic addresses: ono.kouichi.63s@st.kyoto-u.ac.jp; ono@kuaero.kyoto-u.ac.jp; and ono@jwri.osaka-u.ac.jp
}

\begin{abstract}
A microplasma thruster of the electrothermal type has been developed with X-band $(f=11 \mathrm{GHz})$ microwaves and Ar as a propellant. The emphasis was placed on an understanding of distinguished features of the microplasma generation and thrust performance by X-band microwaves, compared with those by S-band $(f=4 \mathrm{GHz})$ ones. The thruster consisted of a microplasma source $2 \mathrm{~mm}$ in the inner diameter and 3-12 mm long with a rod antenna on the axis, followed by a converging-diverging micronozzle. Azimuthally symmetric surface wave-excited plasmas were established by microwaves at powers of $\leq 6 \mathrm{~W}$, with the source pressure in the range $2-50 \mathrm{kPa}$ at flow rates of 10-70 sccm. The plasma generation, nozzle flow, and thrust performance were numerically analyzed using a two-dimensional fluid model, coupled with an electromagnetic model for microwaves interacting with plasmas in the source region. Simulations indicated that higher frequency $f=11 \mathrm{GHz}$ with the source chamber length $L_{s} \approx 1 / 4$ of the driving wavelength $\lambda$ is preferred for the microplasma thruster in terms of efficient plasma generation, gas heating, and thus thrust performance as well as system compactness; moreover, in $f=11 \mathrm{GHz}$ discharges with longer $L_{s} \approx 3 \lambda / 4$, standing-wave striation-like plasma structures occur in the axial direction. Experiments were made for $f=11$ and $4 \mathrm{GHz}$ microwaves with the respective $\mathrm{L}_{\mathrm{s}} \approx \lambda / 4$, where the plasma electron density and gas temperature in the microplasma source were measured by optical emission spectroscopy with a small amount of $\mathrm{H}_{2}$ and $\mathrm{N}_{2}$ added. The electron density and gas temperature were in the range of $(4-12) \times 10^{19} \mathrm{~m}^{-3}$ and $800-1000 \mathrm{~K}$ for $f=11 \mathrm{GHz}$, being $\sim 10 \%-50 \%$ higher than those for $f=4 \mathrm{GHz}$. The thrust performance was also measured by a target-type microthrust stand, giving a thrust, specific impulse, and thrust efficiency in the range $0.2-1.8 \mathrm{mN}, 65-90 \mathrm{~s}$, and $2 \%-14 \%$ for $f=11 \mathrm{GHz}$, which were $\sim 10 \%-15 \%$ higher than those for $f=4 \mathrm{GHz}$. These experimental results were consistent with those of simulations, depending on microwave frequency, power, chamber size, and gas flow rate.
\end{abstract}

Published under license by AIP Publishing. https:/ /doi.org/10.1063/1.5054790

\section{INTRODUCTION}

Small spacecrafts or microspacecrafts have recently attracted much attention in space technology, because of their low costs and short development periods. ${ }^{1-3}$ However, most microspacecrafts do not have any propulsion systems, relying on passive attitude control by using, e.g., gravity gradient stabilization and magnetic torquers. If microspacecrafts had microthrusters on board, they could be controlled and/ or operated more effectively for missions designed to achieve (maneuver to optimum orbits, station keeping, de-orbit at the 
end of mission, constellation with maneuvering, etc.). Owing to the limited power generation and propellant storage on microspacecrafts, high specific impulse, high thrust efficiency, and low power consumption are required for microthrusters, in addition to the small size and a light weight.

A variety of micropropulsion systems or microthrusters have been proposed and developed, including micro electric propulsion systems or micro plasma/ion thrusters; ${ }^{4-13}$ they can be electrostatic, electromagnetic, and electrothermal as with conventional-scale electric thrusters, ${ }^{14}$ each with its own advantages and disadvantages depending on the application and mission. The electrostatic thrusters rely on the ion acceleration by electrostatic fields to achieve the thrust: micro ion thrusters (employing various $\mathrm{dc}, \mathrm{rf}$, and microwave plasma/ ion sources), ${ }^{15-19}$ Hall thrusters (in which the electrostatic fields are produced largely by the actions of plasma electrons interacting with magnetic fields), ${ }^{20,21}$ field emission electron propulsion thrusters, ${ }^{22,23}$ colloid thrusters, ${ }^{24,25}$ and electrodeless thrusters making use of magnetic nozzles; ${ }^{26-30}$ these thrusters require not only grids/electrodes but also a separate system of neutralizers, except that the last ones in which the ambipolar electric fields formed lead to equal currents of ions and electrons leaving the thruster. The electromagnetic thrusters rely on the plasma acceleration via interaction of the current and magnetic fields: micro pulsed plasma thrusters. ${ }^{31,32}$ The electrothermal thrusters rely on the plasma/gas heating via plasma discharge followed by supersonic plasma/ gas expansion through de Laval nozzles: micro arcjet thrusters, ${ }^{33,34}$ hollow cathode thrusters, ${ }^{35}$ and plasma thrusters using dc microdischarges, ${ }^{36,37} \mathrm{ac} / \mathrm{rf}$ microcavity discharges, ${ }^{38,39}$ capacitively coupled $\mathrm{rf}$ discharges in a dielectric tube, ${ }^{40-47}$ and microwave discharges. ${ }^{48,49}$

We have developed a mm-scale microplasma thruster of the electrothermal type with azimuthally symmetric surface

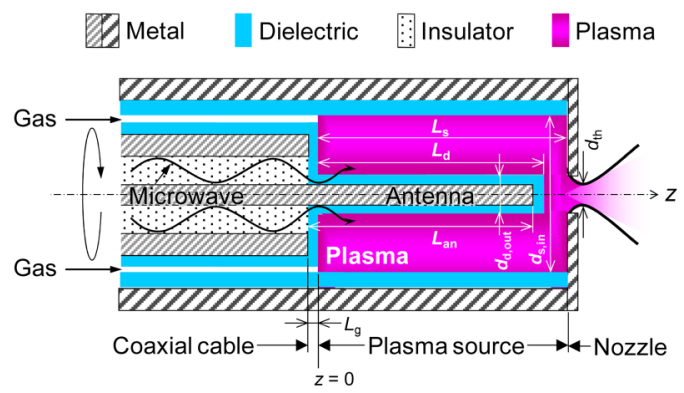

FIG. 1. Schematic of the mm-scale microplasma thruster with azimuthally symmetric SWPs (not to scale), consisting of a microplasma source with a rod antenna on the axis followed by a converging-diverging micronozzle. The dielectric source chamber is $d_{s, \text { in }}=2.04 \mathrm{~mm}$ in the inner diameter and $L_{s}=3-12 \mathrm{~mm}$ long, the dielectric antenna envelope is $d_{d \text {,out }}=1.2 \mathrm{~mm}$ in the outer diameter and $L_{d}=L_{s}-1.0 \mathrm{~mm}$ long, and the nozzle is $1 \mathrm{~mm}$ long in total with a throat $d_{\text {th }}=0.2 \mathrm{~mm}$ in diameter. The $r z$ origin in the numerical analysis is placed at the left end of the plasma source region; the end of the coaxial cable is at $z=-0.6$ $\mathrm{mm}\left(=-L_{g}\right)$, and the antenna length is taken to be $L_{\text {an }}=\left(L_{d}-0.5 \mathrm{~mm}\right)+L_{g}=$ $L_{s}-0.9 \mathrm{~mm}$. wave-excited plasmas (SWPs), ${ }^{50-58}$ consisting of a microplasma source followed by a converging-diverging micronozzle as schematically shown in Fig. 1. The microplasma source is made of a dielectric chamber covered with a grounded metal shroud, having a metal rod antenna on the axis covered with a dielectric envelope, which is powered by microwaves of $<10 \mathrm{~W}$ to produce high temperature (nonthermal or nonequilibrium) plasmas at around atmospheric pressures; and the micronozzle converts the thermal energy of plasmas into the directional kinetic energy of supersonic plasma flows to obtain the thrust. The major feature of SWP is that discharges can be established over a wide pressure range $\left(\sim 10^{-3}-10^{3} \mathrm{~Pa}\right)$ by electromagnetic surface waves excited at plasma-dielectric interfaces without electrodes and magnetic fields; ${ }^{59-64}$ in SWPs, the microwaves penetrate into the plasma along the interfaces even in the overdense mode to heat plasma electrons in a thin (a few $\mathrm{mm}$ thick or less) skin-depth layer. The present configuration of SWP source equipped with a rod antenna on the axis was originally developed for plasma materials processing, ${ }^{65-68}$ being applied to etching of large-diameter substrates (using additionally multipole magnetic fields), ${ }^{66}$ to coating of inner and/or outer surfaces of small-diameter metal tubes, ${ }^{69-71}$ and further to the microplasma thruster; ${ }^{50-58}$ in practice, it has an advantage in efficient plasma generation even in a limited, small space through surface waves excited at annular plasmadielectric interfaces around the rod antenna on the axis.

Previously, we made a comprehensive numerical and experimental investigation of the microplasma generation, micronozzle flow, and thrust performance with 4-GHz microwaves at powers of $\leq 6 \mathrm{~W} ;{ }^{54-57}$ then, a thrust $\mathrm{F}_{t} \leq 1.4 \mathrm{mN}$, specific impulse $I_{\mathrm{sp}} \leq 80 \mathrm{~s}$, and thrust efficiency $\eta_{t} \leq 12 \%$ were obtained with working or propellant gas of $\mathrm{Ar}^{56}$ while $\mathrm{F}_{t} \leq$ $0.51 \mathrm{mN}, \mathrm{I}_{\mathrm{sp}} \leq 270 \mathrm{~s}$, and $\eta_{\mathrm{t}} \leq 12 \%$ were with light He propellant (much higher $\mathrm{I}_{\mathrm{sp}} \leq 450 \mathrm{~s}$ was obtained with $\mathrm{H}_{2}$ ). ${ }^{57}$ We further showed $\mathrm{a} \sim 10 \%$ increase in the thrust performance with $\mathrm{Ar}$ (at maximum), through applying axial magnetic fields at the microplasma source and micronozzle regions (created by a ring permanent magnet axially magnetized). ${ }^{58}$

This paper presents a numerical and experimental study of the microplasma thruster powered by higher frequency X-band $(f=11 \mathrm{GHz})$ microwaves with $\mathrm{Ar}$ as a propellant. The emphasis is placed on a better understanding of the distinguished features of microplasma generation by X-band microwaves, compared with those by S-band $(f=4 \mathrm{GHz})$ ones, and the following micronozzle flow and thrust performance. $\mathrm{X}$-band microwaves have been employed to generate highdensity, high-temperature plasmas under electron cyclotron resonance conditions at low pressures $\left(\sim 10^{-5}-10^{-4} \mathrm{~Pa}\right)$ for use of highly charged ion and short wavelength radiation sources; ${ }^{72-74}$ and a few studies have been concerned with plasma discharges at higher and atmospheric pressures $(\sim 1-50 \mathrm{kPa})$ where the plasma is highly collisional. ${ }^{75}$ Microwave frequency effects on plasma discharges have recently attracted much attention to generate higher density nonthermal microplasmas at atmospheric pressures, ${ }^{76-80}$ from the viewpoint of a fundamental interest in plasma physics / chemistry as well as their applications such as materials 
processing, chemical synthesis, and plasma medicine. However, these studies of microplasmas driven by X-band and much higher frequency microwaves have focused on microstrip-based implementations with interelectrode gaps, ${ }^{76-80}$ where electrons and ions are assumed to be confined in the gap by oscillating electric fields, which results in particle losses to the walls to become negligible, and thus leads to an increase in plasma density ${ }^{79}$ Little research has been conducted on surface waveexcited microplasmas as well as SWPs of conventional scale driven by X-band microwaves.

Section II describes the numerical model and results for the microplasma generation and micronozzle flow, predicting the thrust performance obtained. The numerical investigations are concerned primarily with the plasma generation in response to a change of the length of the plasma source chamber, to find the optimum configuration for the microplasma generation and thus for the thrust performance. Section III gives the experimental setup and results, where the plasma density and gas temperature were measured in the plasma source region by optical emission spectroscopy, along with the thrust performance (thrust, specific impulse, thrust efficiency) achieved. A comparison between numerical and experimental results is made for both $f=11$ and $4 \mathrm{GHz}$ microwaves, and a difference in microplasma generation, micronozzle flow, and thrust performance is discussed between these two microwaves of different frequencies. Finally, Sec. IV summarizes the conclusions of this paper.

It is noted that the configuration of the microplasma source has been slightly redesigned in this study, primarily to resolve electrical issues in experiments for $f=11 \mathrm{GHz}$ microwaves, as will be mentioned later in Sec. III A; in practice, the diameter of the present microplasma source is a little large as compared with the previous configuration, ${ }^{56,57}$ with the micronozzle dimensions remaining unchanged.

\section{NUMERICAL ANALYSIS}

\section{A. Model}

The numerical model consisted of an electromagnetic module (EM) for microwave propagation in interacting with plasma and a fluid module (FM) for plasma flows, which has been detailed in our previous papers. ${ }^{56,57}$ Briefly, the EM was applied to the microplasma source region to analyze the microwave power absorption in the plasma, while the FM to the entire region through the microplasma source to micronozzle (or through subsonic to supersonic) to analyze the plasma and nozzle flow characteristics. Gas-phase reactions were taken into account in both regions along with plasmawall interactions, and the analysis of the nozzle flow finally gave the thrust performance achieved. The numerical analysis was made in the azimuthally symmetric coordinate system (two-dimensional $r-z$ system, $\partial / \partial \theta=0$ ) assuming: (i) a plasma consisting of electrons and heavy particles (ions and neutrals) with two different temperatures $\left[\mathrm{T}_{e} \neq \mathrm{T}_{h}\left(=\mathrm{T}_{i}=\mathrm{T}_{n}\right)\right.$, assuming Maxwellian distributions]; (ii) charge neutrality (plasma electrons and ions have the same density, $n_{e}=n_{i}$ ); (iii) gas-phase atomic processes of electron-impact excitation/deexcitation and ionization/recombination, including metastables as well as ground-state atoms (neutral density $n_{n}=n_{g}+n_{*}$ with ground-state $n_{g}$ and metastable $n *$ ones); (iv) ambipolar diffusion of charged particles (ions and electrons) toward walls; (v) neglecting sheath structures at plasma-wall interfaces; (vi) laminar gas/plasma flow with the same convective velocity $\boldsymbol{v}$ for electrons and heavy particles; and (vii) energy transfer from microwaves to plasma electrons through classical Ohmic heating and then to heavy particles through elastic (momentum transfer) and inelastic (excitation, ionization) collisions between them.

The EM module consisted of Maxwell's equations for electromagnetic fields of microwaves and equations for plasma electrons (neglecting the Lorentz force and pressure gradient). Assuming the azimuthal symmetry, only the transverse magnetic (TM) waves were taken to exist in the plasma source chamber with the electric $\mathbf{E}=\left(E_{r}, 0, E_{z}\right)$ and magnetic $\mathbf{B}=\left(0, B_{\theta}, 0\right)$ fields of microwaves. ${ }^{81,82}$ The transverse electromagnetic (TEM) waves were injected into the system at the excitation plane $(1.2 \mathrm{~mm}$ upstream of the end of the coaxial cable), and the total power injected thereat was monitored as $P_{\text {in }}=\left(1 / \mu_{0}\right) \int_{\mathrm{A}}(\mathbf{E} \times \mathbf{B}) \cdot d \mathbf{A}$, where $\mu_{0}$ is the magnetic permeability of vacuum and $\mathrm{A}$ is the cross section concerned. The boundary conditions for the EM equations were the same as in Refs. 56 and 57, including Mur's first-order absorbing boundary condition ${ }^{83}$ applied to the field component $E_{r}$ at the left end of the coaxial cable $(0.8 \mathrm{~mm}$ further upstream of the excitation plane), so that the electromagnetic waves propagating backward from the chamber to the excitation plane leave the simulation area without any artificial reflection. In addition, the total absorbed power in the plasma was calculated as $P_{a b s}=\int_{V} Q_{a b s} d V=\int_{V}\left[\left(1 / t_{p}\right) \int_{t_{p}} \mathbf{j} \cdot \mathbf{E} d t\right] d V$, where $\mathbf{j}$ is the plasma or electron current density induced by microwaves, $t_{p}$ the period of the electromagnetic waves, and $\mathrm{Q}_{\mathrm{abs}}$ the time-averaged power density absorbed. The spatially averaged power density absorbed per unit volume was given by $\bar{Q}_{\mathrm{abs}}=\mathrm{P}_{\mathrm{abs}} / \mathrm{V}$ with the plasma volume $\mathrm{V}$.

The FM module consisted of two-temperature NavierStokes equations and the equation of state for a two-phase medium consisting of electrons and heavy particles (ions and neutrals): overall mass continuity, overall momentum conservation, conservation of electrons, ${ }^{84}$ conservation of metastables, energy conservation of electrons, energy conservation of heavy particles, and equation of state. The transport coefficients such as viscosity, ambipolar diffusion coefficient, diffusivity, and thermal conductivity for electrons and heavy particles ( $\mathrm{Ar}^{+}$ions, $\mathrm{Ar}{ }^{*}$ metastables, and Ar ground-state atoms) were the same as in Ref. 56, along with the rate coefficients for elastic and inelastic collision processes between electrons and heavy particles and with the corresponding energy exchange and radiative energy loss rates. The boundary conditions for the FM equations were also the same as in Refs. 56 and 57, where the heavy particle temperature $T_{h}$ at the interfaces was assumed to be isothermal with a wall temperature $T_{w}=500 \mathrm{~K}$ in the plasma source region, and to rely on the radiative wall condition in the nozzle region. 
The numerical procedures have also been described in our previous papers. ${ }^{56,57}$ The EM equations for the microplasma source were solved by using the finite difference time-domain (FDTD) approximation, ${ }^{85}$ where the spatial grids were taken to be rectangular with $\Delta r=\Delta z=0.01 \mathrm{~mm}$; note that the numerical scheme concerned was the same as that used before, ${ }^{67,68}$ including the FDTD unit cell, computational grids, electromagnetic fields thereon, and the corresponding difference equations. The FM equations for the entire region through the microplasma source to micronozzle were all discretized in a finite difference manner, and the discrete equations were solved by using an implicit lower-upper symmetric GaussSeidel scheme (LU-SGS). ${ }^{86}$ The spatial grids of the FM in the plasma source region were taken to be the same as those of the EM, while the FM grids in the nozzle region were curvilinear with the grid spacing being finer near the throat in the axial $z$-direction and being regular in the radial $r$-direction. A self-consistent solution was obtained by applying the different timescale integration to the EM and FM modules, where the procedures were repeated until the plasma and flow properties converged in the entire region of the plasma source and the nozzle, to finally give the thrust performance (thrust, specific impulse, thrust efficiency).

The microplasma source (as in Fig. 1) consisted of a dielectric chamber (length $L_{s}$, inner diameter $d_{s, \text { in }}=2.04 \mathrm{~mm}$, outer diameter $d_{s, \text { out }}=6.0 \mathrm{~mm}$ ) covered with a metal shroud grounded, having a metal rod antenna (length $L_{a n}$, diameter $d_{\mathrm{an}}=0.48 \mathrm{~mm}$ ) on the axis covered with a dielectric envelope (length $L_{d}$, inner diameter $d_{d \text {,in }}=d_{\text {an }}=0.48 \mathrm{~mm}$, outer diameter $d_{d \text {,out }}=1.2 \mathrm{~mm}$ ). Here, the lengths of the antenna envelope and the antenna were taken to be $L_{d}=L_{s}-1.0 \mathrm{~mm}$ and $L_{\text {an }}$ $=\left(\mathrm{L}_{d}-0.5 \mathrm{~mm}\right)+\mathrm{L}_{g}=\mathrm{L}_{\mathrm{s}}-0.9 \mathrm{~mm}$, respectively, with a distance $\mathrm{L}_{g}=0.6 \mathrm{~mm}$ between the end of the coaxial cable and the left end of the annular plasma region; the antenna was connected to the center conductor of the coaxial cable, and its shield or outer conductor was connected to ground. The micronozzle at the end of the microplasma source had an inlet, throat, and exit diameter of $d_{\text {in }}=0.6 \mathrm{~mm}, d_{\mathrm{th}}=0.2 \mathrm{~mm}$, and $d_{\mathrm{ex}}=0.8 \mathrm{~mm}$, respectively, with a diverging angle of $\theta=26.6^{\circ}$ and a total length of $1 \mathrm{~mm}$. In addition, the dielectric plasma source chamber and antenna envelope were assumed to be made of quartz (relative permittivity $\varepsilon_{r}=\varepsilon_{d}=3.8$ ), and the dielectric/ insulator of the coaxial cable was of polytetrafluoroethylene (PTFE, $\varepsilon_{r}=\varepsilon_{i}=2.1$ ); all metallic parts were treated as perfectly conducting materials, where the electric field components tangential to metal surfaces were set to be zero.

\section{B. Numerical results}

Simulations were made by varying the length of the microplasma source chamber in the range $L_{s}=3-12 \mathrm{~mm}$ (typically $L_{\mathrm{s}}=4.5$ and $10.5 \mathrm{~cm}$ for $f=11$ and $4 \mathrm{GHz}$, respectively), to find the optimum configurations for the microplasma generation and thus for the thrust performance. The input power of $f=11$ and $4 \mathrm{GHz}$ microwaves was taken to be $P_{\text {in }}=6 \mathrm{~W}$, and the mass flow rate of the Ar propellant was $\dot{m}=1.5 \mathrm{mg} / \mathrm{s}$ (a flow rate of $50 \mathrm{sccm})$, unless otherwise stated.

\section{Microplasma generation by $\mathrm{f}=11 \mathrm{GHz}$ microwaves}

Figures 2(a)-2(h) show the spatial distribution of the electron density $n_{e}$, electron temperature $\mathrm{T}_{e}$, heavy particle temperature $T_{h}$, absorbed power density $\mathrm{Q}_{\text {abs }}$, pressure $p$, axial flow velocity $u$, Ar gas or ground-state density $n_{g}$, and Ar* metastable-state density $n_{*}$ in the microplasma source, respectively, simulated for $f=11 \mathrm{GHz}$ with a plasma chamber length $L_{\mathrm{s}}=4.5 \mathrm{~mm}$ (case I). Here, the pressure is given by $p=$ $p_{e}+p_{h}=n_{e} k_{\mathrm{B}} \mathrm{T}_{e}+n_{h} k_{\mathrm{B}} \mathrm{T}_{h}=n_{e} k_{\mathrm{B}}\left(\mathrm{T}_{e}+\mathrm{T}_{h}\right)+n_{n} k_{\mathrm{B}} \mathrm{T}_{h} \approx n_{g} k_{\mathrm{B}} \mathrm{T}_{h} \quad$ with the Boltzmann constant $k_{\mathrm{B}}$, and the mass density is given by $\rho=m_{e} n_{e}+m_{h} n_{h} \approx m_{h} n_{g}$ with the mass $m_{h} \quad\left(=m_{i}=m_{n}\right)$ and density $n_{h}\left(=n_{i}+n_{n} \approx n_{g}\right)$ of heavy particles. The absorbed power calculated in the plasma is $\mathrm{P}_{\mathrm{abs}} \approx 5.1 \mathrm{~W}$ in total $\left(\mathrm{P}_{\mathrm{abs}} /\right.$ $\mathrm{P}_{\text {in }} \approx 85 \%$ ), corresponding to the average power density $\overline{\mathrm{Q}}_{\mathrm{abs}}=\mathrm{P}_{\mathrm{abs}} / \mathrm{V} \approx 5.0 \times 10^{8} \mathrm{~W} / \mathrm{m}^{3}$. Note that the microwave power not absorbed in the plasma is taken to be reflected at the source ends $\left(r>d_{\text {in }} / 2=0.3 \mathrm{~mm}\right)$, and/or to be passing through the source-nozzle boundaries $\left(r<d_{\text {in }} / 2\right)$ to leave the simulation area. The plasma electron density and temperature exhibit their maxima $\left(n_{e} \approx 1.2 \times 10^{20} \mathrm{~m}^{-3}, \mathrm{~T}_{e} \approx 1.5 \times 10^{4} \mathrm{~K}\right)$ at one axial position, near the end of the antenna envelope, which is consistent with the distribution of $\mathrm{Q}_{\mathrm{abs}}$ as mentioned below. On the other hand, the heavy particle temperature exhibits its maximum $\left(T_{h} \approx 950 \mathrm{~K}\right)$ in a space between the end of the antenna envelope and the end wall of the plasma source chamber, where the micronozzle is located to achieve the aerodynamic acceleration of high temperature plasmas/gases through supersonic expansion into vacuum. In addition, the pressure is almost uniform in the plasma source $(p \approx 35 \mathrm{kPa})$, and the flow velocity is increased in the axial direction toward the end of the source region (up to $u \approx 33 \mathrm{~m} / \mathrm{s}$ ).

Also shown in Figs. 2(i) and 2(j) are typical snapshots of the distribution of the radial $E_{r}$ and axial $E_{z}$ electric fields of $f$ $=11 \mathrm{GHz}$ microwaves for $L_{\mathrm{s}}=4.5 \mathrm{~mm}$, respectively, taken at the time when the electric fields reach peak values in a microwave period. The corresponding extended views of the electric fields in the dielectric as well as in the plasma are shown in Figs. 3(a) and 3(b). These exhibit characteristic of SWPs: ${ }^{59-64}$ the strength of $E_{r}$ is more than ten times smaller than that of $E_{z}$ in the plasma, while the former is about ten times larger than the latter in the dielectric; moreover, the peak positions of the absorbed power density $Q_{a b s}$ in the plasma [Fig. 2(d)] correspond to those of $E_{z}$ (not $E_{r}$ ), implying that the axial $E_{z}$ is the major component of microwave electric fields that contributes to $Q_{a b s}$ and thus to $P_{a b s}$, where the $Q_{a b s}$ and the field strength $\left|E_{z}\right|$ are larger closer to plasmadielectric interfaces. In effect, the $\mathrm{Q}_{\mathrm{abs}}$ and $\left|\mathrm{E}_{z}\right|$ exhibit their peaks $\left[\mathrm{Q}_{\mathrm{abs}} \approx(10-12) \times 10^{8} \mathrm{~W} / \mathrm{m}^{3},\left|\mathrm{E}_{z}\right| \approx(22-25) \times 10^{2} \mathrm{~V} / \mathrm{m}\right]$ at two local positions: $(r, z)=(0.6 \mathrm{~mm}, \sim 0.5 \mathrm{~mm})$ at the inner plasma-dielectric interfaces, and $(r, z)=(1.02 \mathrm{~mm}, \sim 4.5 \mathrm{~mm})$ at the outer ones. The high absorption efficiency $\mathrm{P}_{\mathrm{abs}} / \mathrm{P}_{\text {in }} \approx 85 \%$ is ascribed to the localized absorption of microwaves or inhomogeneous heating of electrons in the interaction of electromagnetic waves with spatially nonuniform plasmas.

Figures 4(a)-4(h) show the distribution of plasma properties in the microplasma source simulated for $f=11 \mathrm{GHz}$ with 
(a) Electron density $n_{\mathrm{e}}\left(10^{18} \mathrm{~m}^{-3}\right)$

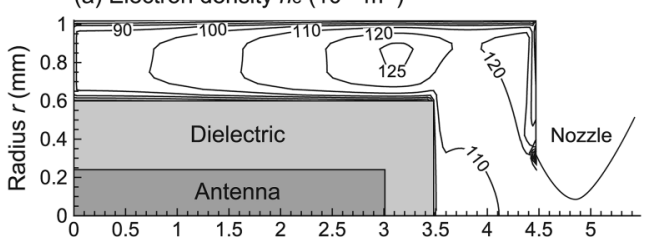

(c) Heavy particle temperature $T_{\mathrm{h}}(\mathrm{K})$

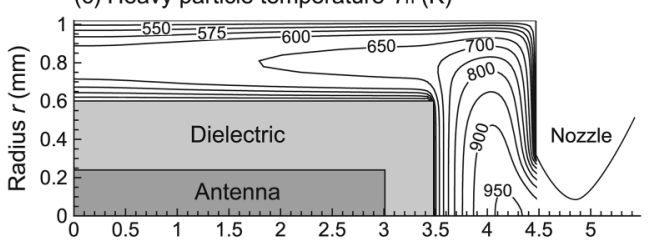

(e) Gas pressure $p(\mathrm{kPa})$

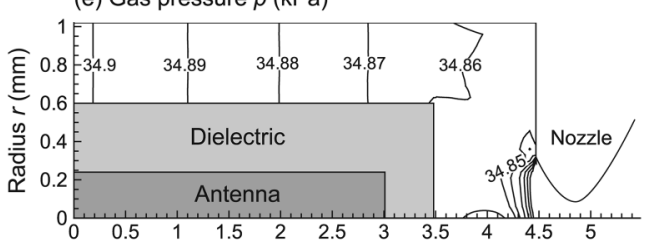

(g) Ground state density $n_{\mathrm{g}}\left(10^{21} \mathrm{~m}^{-3}\right)$
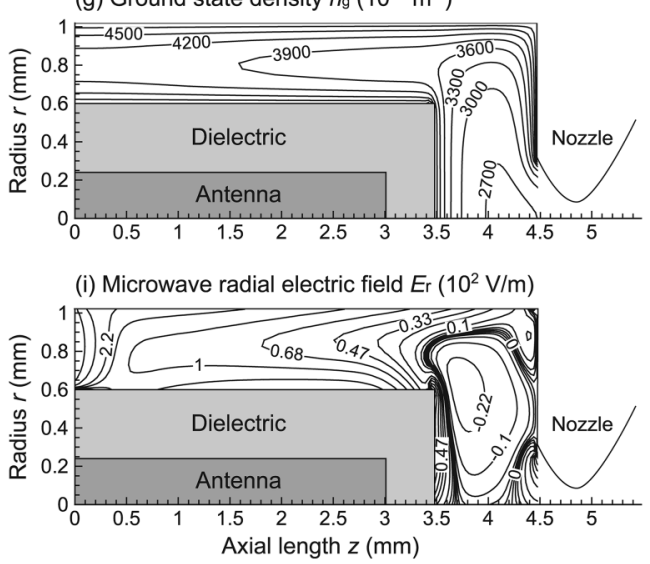

(b) Electron temperature $T_{\mathrm{e}}\left(10^{3} \mathrm{~K}\right)$

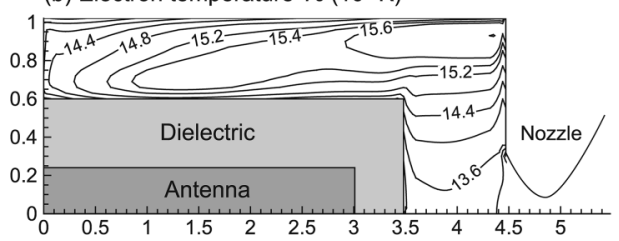

(d) Absorbed power density Qabs $\left(10^{6} \mathrm{~W} / \mathrm{m}^{3}\right)$

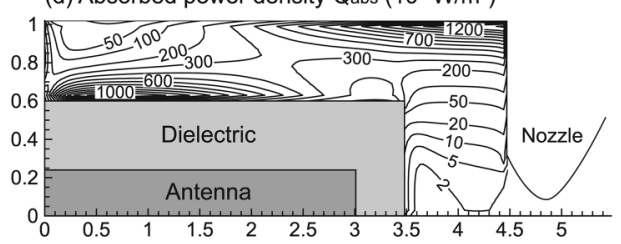

(f) Axial flow velocity $u(\mathrm{~m} / \mathrm{s})$

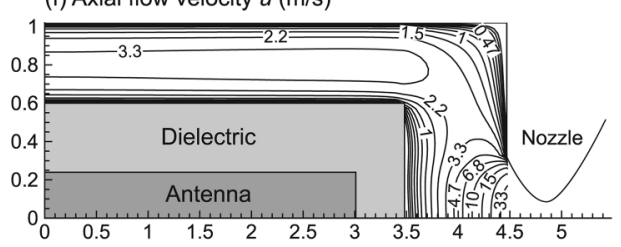

(h) Metastable state density $n_{*}\left(10^{21} \mathrm{~m}^{-3}\right)$

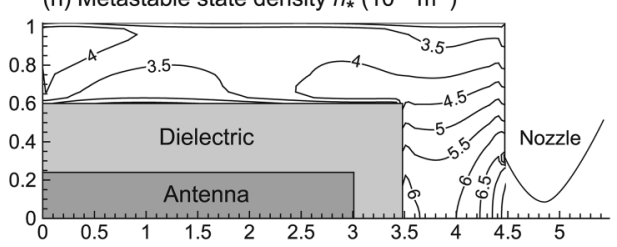

(j) Microwave axial electric field $E_{z}\left(10^{2} \mathrm{~V} / \mathrm{m}\right)$

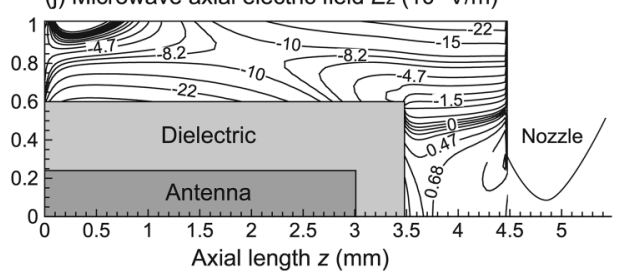

FIG. 2. Distribution of plasma properties in the microplasma source of $L_{s}=4.5 \mathrm{~mm}$, simulated with $f=11 \mathrm{GHz}$ microwaves of $P_{\text {in }}=6.0 \mathrm{~W}$ and an Ar mass flow rate of $\dot{m}=1.5 \mathrm{mg} / \mathrm{s}$ : (a) $n_{e}$, (b) $T_{e}$, (c) $T_{h}$, (d) $Q_{\mathrm{abs}}$, (e) $p$, (f) $u$, (g) $n_{g}\left(\rho \approx m_{h} n_{g}\right.$ ), and (h) $n_{*}$. Here, the antenna has $d_{\mathrm{an}}=0.48 \mathrm{~mm}$ and $L_{\mathrm{an}}=3.6 \mathrm{~mm}$ (from $z=-0.6$ to 3.0 $\mathrm{mm}$ ), the dielectric envelope covering the antenna has $d_{d, \text { in }}=0.48 \mathrm{~mm}\left(=d_{\mathrm{an}}\right), d_{d, \text { out }}=1.2 \mathrm{~mm}$, and $L_{d}=3.5 \mathrm{~mm}$ (from $z=0$ to $3.5 \mathrm{~mm}$ ), and the dielectric chamber of the microplasma source has $d_{s, \text { in }}=2.04 \mathrm{~mm}, d_{s, \text { out }}=6.0 \mathrm{~mm}$, and $L_{s}=4.5 \mathrm{~mm}$ (from $z=0$ to $4.5 \mathrm{~mm}$ ). The microwave power absorbed in the plasma was calculated as $P_{\text {abs }} \approx$ $5.1 \mathrm{~W}$. Also shown are snapshots of the distribution of microwave electric fields (i) $E_{r}$ and (j) $E_{z}$ in the microplasma source, taken at the time when the electric fields reach peak values in a microwave period.

longer $L_{s}=10.5 \mathrm{~mm}$ (case II). The absorbed power in the plasma is $\mathrm{P}_{\mathrm{abs}} \approx 3.5 \mathrm{~W}\left(\mathrm{P}_{\mathrm{abs}} / \mathrm{P}_{\mathrm{in}} \approx 58 \%\right)$, corresponding to the average power density $\overline{\mathrm{Q}}_{\mathrm{abs}}=\mathrm{P}_{\mathrm{abs}} / \mathrm{V} \approx 1.6 \times 10^{8} \mathrm{~W} / \mathrm{m}^{3}$. The plasma electron density and temperature exhibit their maxima $\left[n_{e} \approx(0.62-0.65) \times 10^{20} \mathrm{~m}^{-3}, \quad \mathrm{~T}_{e} \approx 1.5 \times 10^{4} \mathrm{~K}\right]$ at two axial positions, near the end of the antenna envelope and at $\sim 6 \mathrm{~mm}$ upstream therefrom, where the heavy particle temperature also appears to exhibit its local maxima $\left(\mathrm{T}_{h} \approx 550 \mathrm{~K}\right.$ ); these distributions are also consistent with that of the absorbed power density $\mathrm{Q}_{\mathrm{abs}}$ as mentioned below. The temperature $T_{h}$ exhibits its maximum $\left(T_{h} \approx 700 \mathrm{~K}\right)$ in a space at the end of the plasma source chamber. Compared with Figs. $2(\mathrm{a})-2(\mathrm{~h})$ for $L_{\mathrm{s}}=4.5 \mathrm{~mm}$, the longer $L_{s}=10.5 \mathrm{~mm}$ leads to a significant $(\sim 30 \%-70 \%)$ decrease in electron density $n_{e}$, heavy particle temperature $T_{h}$, absorbed power density $Q_{a b s}$ (thus, $P_{\text {abs }}$ and $\bar{Q}_{\text {abs }}$ ), and metastable density $n *$; on the other 
(a) Microwave radial electric field $E_{r}\left(10^{2} \mathrm{~V} / \mathrm{m}\right)$

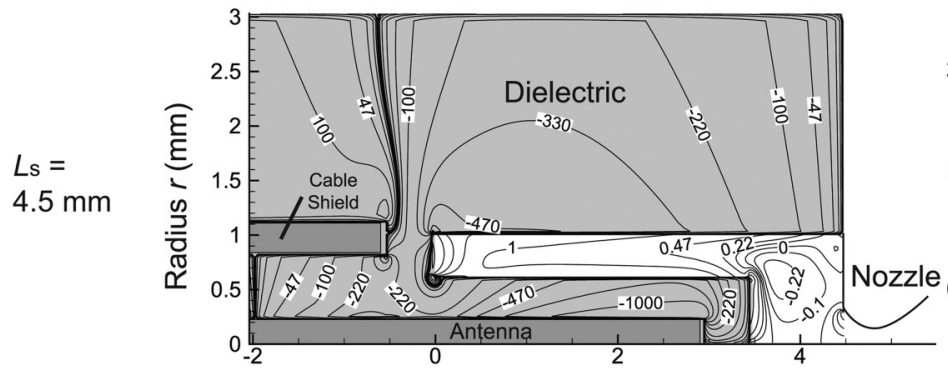

(c) Microwave radial electric field $E_{r}\left(10^{2} \mathrm{~V} / \mathrm{m}\right)$

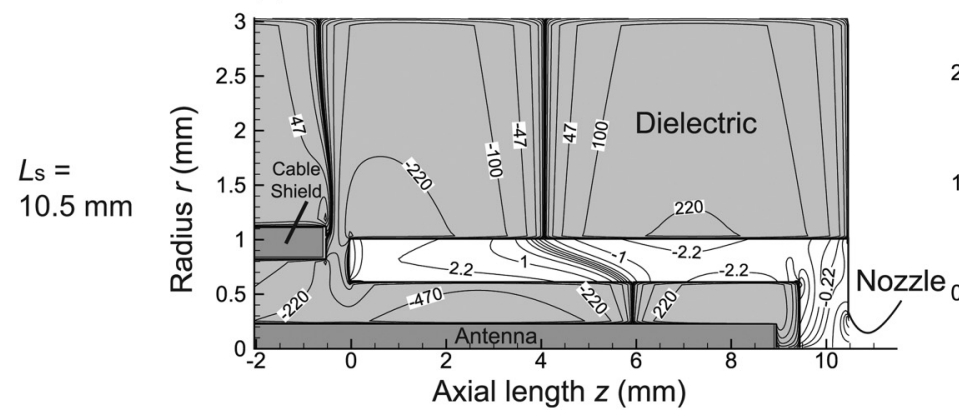

(b) Microwave axial electric field $E_{z}\left(10^{2} \mathrm{~V} / \mathrm{m}\right)$

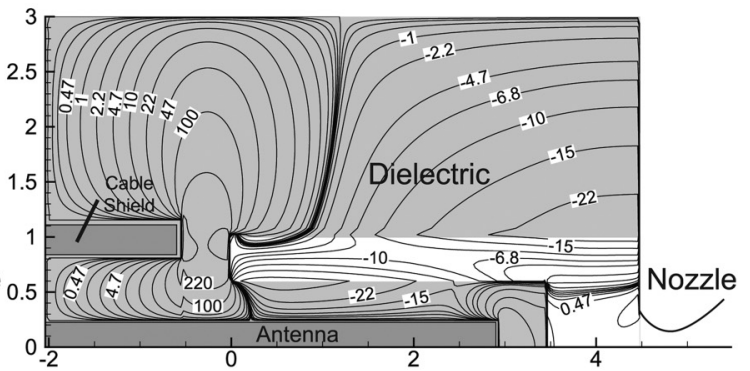

(d) Microwave axial electric field $E_{z}\left(10^{2} \mathrm{~V} / \mathrm{m}\right)$

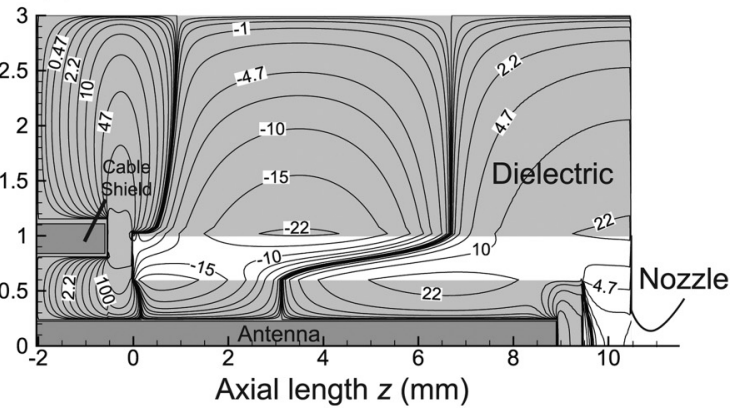

FIG. 3. Extended views of a snapshot of the distribution of microwave electric fields (a) $E_{r}$ and (b) $E_{z}$ in the microplasma source $\left(f=11 \mathrm{GHz}, L_{s}=4.5 \mathrm{~mm}\right)$, corresponding to the preceding Figs. 2(i) and 2(j). Also shown are those of (c) $E_{r}$ and (d) $E_{z}\left(f=11 \mathrm{GHz}, L_{s}=10.5 \mathrm{~mm}\right)$, corresponding to the following Figs. 4 (i) and $4(\mathrm{j})$. Here, the figure includes the region of the coaxial cable for microwave injection and the region of the dielectric plasma chamber and antenna envelope. Note that the left end of the plasma source chamber is at $z=0$, the end of the coaxial cable is at $z=-0.6 \mathrm{~mm}$, the excitation plane for microwave injection in the numerical analysis is at $z=-1.8 \mathrm{~mm}$, and the boundary for Mur's first-order absorbing condition is at $z=-2.6 \mathrm{~mm}$ (out of the figure).

hand, the electron temperature $\mathrm{T}_{e}$, pressure $p$, flow velocity $u$, and gas or ground-state density $n_{g}$ remain relatively unchanged.

Also shown in Figs. 4(i) and 4(j) are typical snapshots of the distribution of the radial $E_{r}$ and axial $E_{z}$ electric fields of $f=11 \mathrm{GHz}$ microwaves for $L_{s}=10.5 \mathrm{~mm}$, respectively, and the corresponding extended views of the electric fields in the dielectric as well as in the plasma are shown in Figs. 3(c) and 3(d). These also exhibit characteristics of SWPs: ${ }^{59-64}$ the peak positions of the absorbed power density $\mathrm{Q}_{\mathrm{abs}}$ in the plasma [Fig. 4(d)] correspond to those of $E_{z}$, where the $Q_{a b s}$ and the field strength $\left|E_{z}\right|$ are larger closer to plasma-dielectric interfaces. In effect, the $Q_{\text {abs }}$ and $\left|E_{z}\right|$ exhibit their peaks $\left[\mathrm{Q}_{\mathrm{abs}} \approx(3.0-3.5) \times 10^{8} \mathrm{~W} / \mathrm{m}^{3},\left|\mathrm{E}_{z}\right| \approx(15-22) \times 10^{2} \mathrm{~V} / \mathrm{m}\right]$ at four local positions: $(r, z)=(0.6 \mathrm{~mm}, \sim 0.7$ and $\sim 6.7 \mathrm{~mm})$ at the inner plasma-dielectric interfaces, and $(r, z)=(1.02 \mathrm{~mm}, \sim 3.5$ and $\sim 10.5 \mathrm{~mm}$ ) at the outer ones. These microwave fields and thus absorption structures are considered to cause the plasma structures having two local maxima of $n_{e}, \mathrm{~T}_{e}$, and $\mathrm{T}_{h}$, whose positions are separated by $\Delta z \sim 6 \mathrm{~mm}$; similar structures have been observed in experiments of planar $^{87}$ and linear ${ }^{88-90}$ SWPs $(f=2.45 \mathrm{GHz})$ of conventional scale, where the latter showed periodic local peaks of the electron density ${ }^{88}$ and the optical emission intensity ${ }^{89,90}$ along the axis. Compared with Figs. 2(i), 2(j), 3(a), and $3(\mathrm{~b})$ for $\mathrm{L}_{\mathrm{s}}=4.5 \mathrm{~mm}$, the longer
$L_{s}=10.5 \mathrm{~mm}$ gives a conspicuous sign reversal for both $E_{r}$ and $E_{z}$ across the annular plasma region at around the middle of the antenna envelope or the plasma source chamber (though their peak strengths remain almost the same); this reflects a node of standing electromagnetic waves or surface waves that occurs thereat, which in turn results in decreased $Q_{a b s}$ and thus in decreased $P_{a b s}$ and $\bar{Q}_{a b s}$ for $L_{s}=10.5 \mathrm{~mm}$.

It should be noted that in extended views of Figs. 3(c) and $3(d)$ for $L_{s}=10.5 \mathrm{~mm}$, the node of standing waves is seen to extend in the dielectric; e.g., the node $E_{z}=0$ in Fig. $3(\mathrm{~d})$ is at $z \approx 6.5 \mathrm{~mm}$ in the plasma chamber dielectric $\left(d_{\mathrm{s}, \text { in }} / 2=1.02\right.$ $\mathrm{mm} \leq r \leq d_{\mathrm{s}, \text { out }} / 2=3.0 \mathrm{~mm}$ ) and at $z \approx 3 \mathrm{~mm}$ in the dielectric of the antenna envelope $\left(d_{d, \text { in }} / 2=0.24 \mathrm{~mm} \leq r \leq d_{d \text {,out }} / 2=0.6\right.$ $\mathrm{mm}$ ), being connected with that located at $z \approx 3-6.5 \mathrm{~mm}$ across the annular plasma region $\left(d_{d, \text { out }} / 2=0.6 \mathrm{~mm} \leq r \leq d_{s}\right.$, in $/ 2=1.02 \mathrm{~mm}$ ). Correspondingly, the antinodes having $\left|E_{z}\right|$ peaks can be seen on both sides of the node $E_{z}=0$ : they are at $z \approx 3.5$ and $10.5 \mathrm{~mm}$ in the plasma chamber dielectric and at the outer plasma-dielectric interfaces $(1.02 \leq r \leq 3.0 \mathrm{~mm})$, and at $z \approx 0.7$ and $6.7 \mathrm{~mm}$ in the antenna envelope dielectric and at the inner plasma-dielectric interfaces $(0.24 \leq r \leq 0.6 \mathrm{~mm})$, giving the half-wavelength $\lambda_{\mathrm{sw}} / 2 \approx 6-7 \mathrm{~mm}$ and thus the wavelength $\lambda_{\mathrm{sw}} \approx 12-14 \mathrm{~mm}$ of the waves.

It should be further noted that in Figs. 2(i), 2(j), 3(a), and 3(b) for $L_{s}=4.5 \mathrm{~mm}$, the sign reversal for $E_{r}$ and $E_{z}$ in the 
(a) Electron density $n_{e}\left(10^{18} \mathrm{~m}^{-3}\right)$

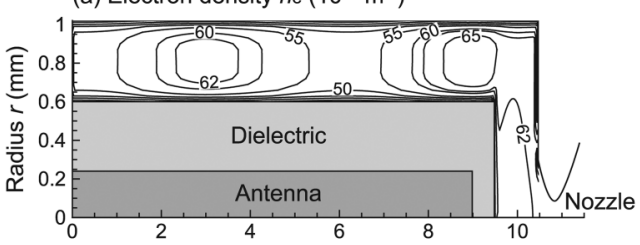

(c) Heavy particle temperature $\mathrm{Th}(\mathrm{K})$

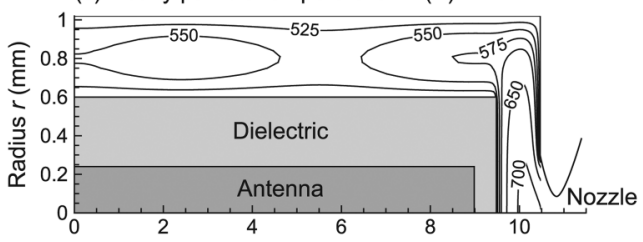

(e) Gas pressure $p(\mathrm{kPa})$

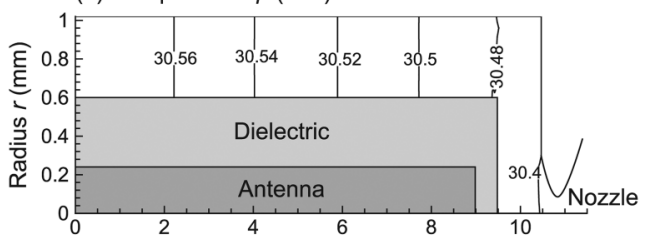

(g) Ground state density $n_{\mathrm{g}}\left(10^{21} \mathrm{~m}^{-3}\right)$

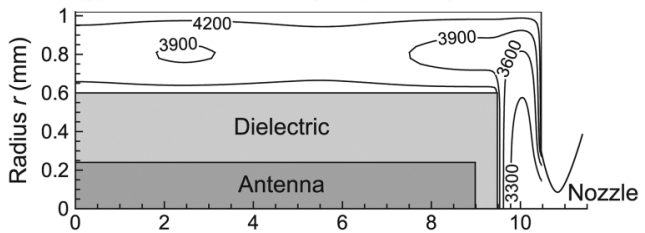

(i) Microwave radial electric field $\operatorname{Er}\left(10^{2} \mathrm{~V} / \mathrm{m}\right)$

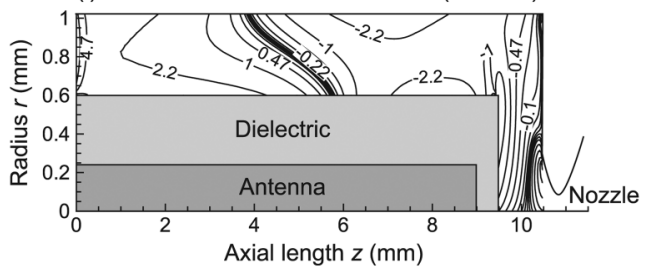

(b) Electron temperature $T_{\mathrm{e}}\left(10^{3} \mathrm{~K}\right)$

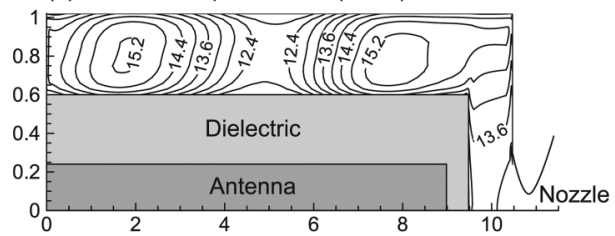

(d) Absorbed power density Qabs $\left(10^{6} \mathrm{~W} / \mathrm{m}^{3}\right)$

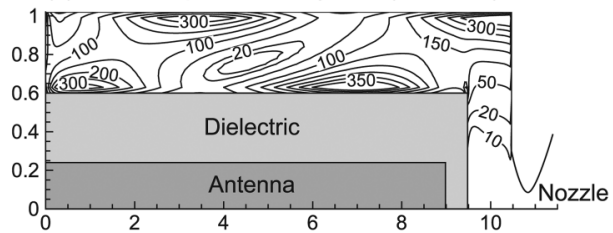

(f) Axial flow velocity $u(\mathrm{~m} / \mathrm{s})$

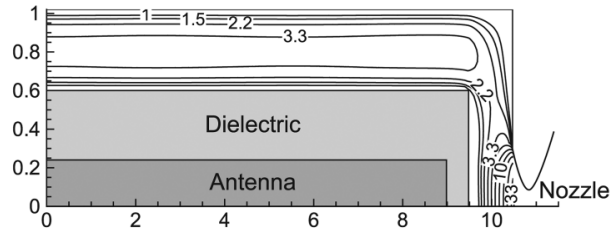

(h) Metastable state density $n_{\star}\left(10^{21} \mathrm{~m}^{-3}\right)$

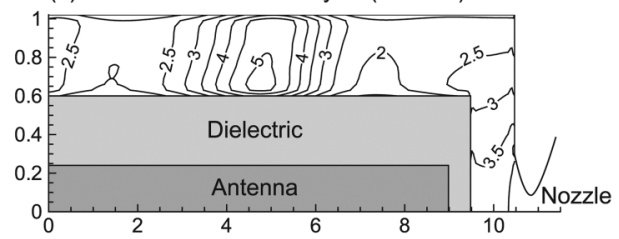

(j) Microwave axial electric field $E_{z}\left(10^{2} \mathrm{~V} / \mathrm{m}\right)$

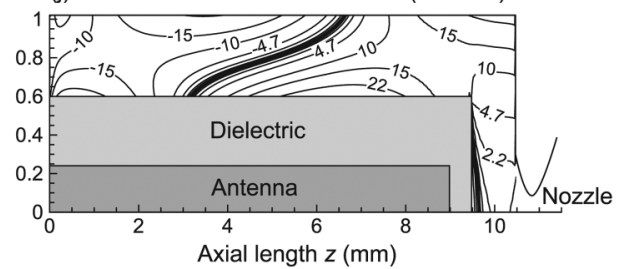

FIG. 4. Distribution of plasma properties in the microplasma source of $L_{s}=10.5 \mathrm{~mm}$, simulated with the operating conditions that are the same as in Fig. 2 ( $f=11 \mathrm{GHz}$, $P_{\text {in }}=6.0 \mathrm{~W}, \dot{m}=1.5 \mathrm{mg} / \mathrm{s}$ ): (a) $n_{e}$, (b) $T_{e}$, (c) $T_{h}$, (d) $Q_{\text {abs }}$, (e) $p$, (f) $u,(\mathrm{~g}) n_{g}\left(\rho \approx m_{h} n_{g}\right)$, and (h) $n_{*}$. Also shown are snapshots of the distribution of microwave electric fields (i) $E_{r}$ and (j) $E_{z}$ in the microplasma source. Here, the figure properties are the same as in Fig. 2 , except for the following axial lengths: $L_{a n}=9.6 \mathrm{~mm}$ (from $z=-0.6$ to $9.0 \mathrm{~mm}$ ), $L_{d}=9.5 \mathrm{~mm}$ (from $z=0$ to $9.5 \mathrm{~mm}$ ), and $L_{s}=10.5 \mathrm{~mm}$ (from $z=0$ to $10.5 \mathrm{~mm}$ ). The microwave power absorbed in the plasma was calculated as $P_{\text {abs }} \approx 3.5 \mathrm{~W}$.

plasma is relatively inconspicuous, which is seen to occur in a space between the end of the antenna envelope and the end wall of the plasma source chamber; e.g., the node $E_{z}=0$ of standing waves in Figs. 2(j) and 3(b) does not occur in the plasma chamber dielectric $(1.02 \leq r \leq 3.0 \mathrm{~mm})$, while it occurs at $z \approx 2.5 \mathrm{~mm}$ in the dielectric of the antenna envelope $(0.24 \leq r \leq 0.6 \mathrm{~mm})$, being connected with that in the plasma region via that along the inner plasma-dielectric interfaces $(r=0.6 \mathrm{~mm})$. The antinodes having $\left|E_{z}\right|$ peaks can be seen at $z \approx 4.5 \mathrm{~mm}$ in the plasma chamber dielectric and at the outer plasma-dielectric interfaces $(1.02 \leq r \leq 3.0 \mathrm{~mm})$, and at $z \approx 0.5 \mathrm{~mm}$ in the antenna envelope dielectric and at the inner plasma-dielectric interfaces $(0.24 \leq r \leq 0.6 \mathrm{~mm})$. These suggest the quarter-wavelength $\lambda_{\mathrm{sw}} / 4 \approx 3-3.5 \mathrm{~mm}$ (between $z \approx 1$ and $4.5 \mathrm{~mm}$ at the outer $r=1.02 \mathrm{~mm}$ and between $z \approx 0.5$ and $3.5 \mathrm{~mm}$ at the inner $r=0.6 \mathrm{~mm}$ ), and thus the wavelength $\lambda_{\mathrm{sw}} \approx 12-14 \mathrm{~mm}$ of the waves.

The wavelength of electromagnetic waves of frequency $f=\omega / 2 \pi$ propagating in the unbounded dielectric is given by $\lambda=\lambda_{0} / n=\lambda_{0} / \sqrt{\varepsilon_{d}}$ (TEM traveling waves), where $\lambda_{0}=c / f$ is 
the wavelength in vacuum, $c$ is the speed of light in vacuum, and $n$ is the refractive index of the dielectric. In practice, $f=11 \mathrm{GHz}$ and $\varepsilon_{r}=\varepsilon_{d}=3.8$ (quartz) give $\lambda=13.97 \mathrm{~mm}(3 \lambda /$ $4=10.47 \mathrm{~mm}, \lambda / 2=6.98 \mathrm{~mm}, \lambda / 4=3.49 \mathrm{~mm})$, which corresponds to the $\lambda_{\mathrm{sw}}$ estimated as above from the results of numerical simulations for $L_{\mathrm{s}}=4.5$ and $10.5 \mathrm{~mm}$. Thus, we consider that the driving microwave wavelength $\lambda$ is a measure of the wavelength $\lambda_{\mathrm{sw}}$ of standing surface waves excited under the present conditions, and that the plasma chamber lengths $L_{\mathrm{s}}=4.5$ and $10.5 \mathrm{~mm}$ correspond approximately to $1 / 4$ and $3 / 4$ of the driving wavelength $\lambda$ of $f=11 \mathrm{GHz}$ microwaves. Note that our previous analysis ${ }^{50}$ of the dispersion relation for the electromagnetic waves propagating along an infinitely long plasma column inside a circular dielectric tube (2 and $3.2 \mathrm{~mm}$ in the inner and outer diameter, $\varepsilon_{r}=\varepsilon_{d}=3.8$ ) covered with a metal grounded gives the wavelength of azimuthally symmetric surface waves excited (TM traveling waves): $\lambda_{\text {sw }}=7.02-8.72 \mathrm{~mm}$ for $f=11 \mathrm{GHz}$ assuming uniformly distributed plasmas of $n_{e}=(0.6-1.2) \times 10^{20} \mathrm{~m}^{-3}$ in the tube. The discrepancy of the wavelength $\lambda_{\mathrm{sw}}$ between the numerical simulations and dispersion relation analysis may be attributed to the present plasma source configuration of a complex geometry (and partly to a difference between standing and traveling surface waves).

\section{Comparison with $\mathrm{f}=4 \mathrm{GHz}$ microwaves}

The wavelength of electromagnetic waves of $f=4 \mathrm{GHz}$ propagating in the unbounded dielectric $\left(\varepsilon_{r}=\varepsilon_{d}=3.8\right)$ is evaluated to be $\lambda=38.44 \mathrm{~mm}(3 \lambda / 4=28.83 \mathrm{~mm}, \lambda / 2=19.22 \mathrm{~mm}$, $\lambda / 4=9.61 \mathrm{~mm})$. Thus, based on discussions in Sec. II B 1 , we may consider that for $f=4 \mathrm{GHz}$ microwaves under the present conditions, the plasma chamber length $L_{s}=10.5 \mathrm{~mm}$ corresponds approximately to $1 / 4$ of the driving wavelength $\lambda$, or the wavelength $\lambda_{\mathrm{sw}}$ of standing surface waves excited, while $\mathrm{L}_{\mathrm{s}}=4.5 \mathrm{~mm}$ is much shorter than $\lambda / 4 \approx \lambda_{\mathrm{sw}} / 4$.

Figures $5(\mathrm{a})-5(\mathrm{j})$, together with Figs. 6(a) and 6(b), show the distribution of plasma and microwave properties in the microplasma source simulated for $f=4 \mathrm{GHz}$ with $L_{\mathrm{s}}=10.5 \mathrm{~mm}$ (case III, $L_{s} \approx \lambda / 4$ ). The simulations exhibit qualitatively similar contours of plasma and microwave properties to those in Figs. 2(a) $-2(\mathrm{j}), 3(\mathrm{a})$, and $3(\mathrm{~b})$ for $f=11 \mathrm{GHz}$ with $\mathrm{L}_{\mathrm{s}}=4.5 \mathrm{~mm}$ (case $\mathrm{I}, \mathrm{L}_{\mathrm{s}} \approx \lambda / 4$ ). However, the $f=4 \mathrm{GHz}$ with $\mathrm{L}_{\mathrm{s}}=10.5 \mathrm{~cm}$ gives a significant ( $20 \%-70 \%)$ decrease in magnitude of the plasma and microwave absorption properties $\left(n_{e}, \mathrm{~T}_{h}, \mathrm{Q}_{\mathrm{abs}}, n_{*}\right)$, compared with those for $f=11 \mathrm{GHz}$ with $L_{s}=4.5 \mathrm{~mm}$, except the $\mathrm{T}_{e}, p, u$, and $n_{g}$ that remain relatively unchanged. The absorbed power calculated in the plasma is $\mathrm{P}_{\mathrm{abs}} \approx 4.5 \mathrm{~W}$ $\left(\mathrm{P}_{\mathrm{abs}} / \mathrm{P}_{\text {in }} \approx 75 \%\right)$, corresponding to the average power density $\overline{\mathrm{Q}}_{\mathrm{abs}}=\mathrm{P}_{\mathrm{abs}} / \mathrm{V} \approx 2.0 \times 10^{8} \mathrm{~W} / \mathrm{m}^{3}$. The plasma electron density and temperature exhibit their maxima $\left(n_{e} \approx 0.90 \times 10^{20} \mathrm{~m}^{-3}\right.$, $\mathrm{T}_{e} \approx 1.6 \times 10^{4} \mathrm{~K}$ ) at one axial position, near the end and middle of the antenna envelope, respectively. The heavy particle temperature exhibits its maximum $\left(T_{h} \approx 750 \mathrm{~K}\right)$ in a space at the end of the plasma source chamber. The distribution of the radial $E_{r}$ and axial $E_{z}$ electric fields of $f=4 \mathrm{GHz}$ microwaves also reflects characteristics of SWPs, ${ }^{59-64}$ where the absorbed power density $\mathrm{Q}_{\mathrm{abs}}$ and the field strength $\left|E_{z}\right|$ in the plasma are larger closer to plasma-dielectric interfaces. In effect, the $\mathrm{Q}_{\mathrm{abs}}$ and $\left|\mathrm{E}_{z}\right|$ exhibit their peaks $\left[\mathrm{Q}_{\mathrm{abs}} \approx(3.0-3.5) \times 10^{8} \mathrm{~W} / \mathrm{m}^{3},\left|\mathrm{E}_{z}\right| \approx(12-15) \times 10^{2} \mathrm{~V} / \mathrm{m}\right]$ at two local positions: $(r, z)=(0.6 \mathrm{~mm}, \sim 2 \mathrm{~mm})$ at the inner plasmadielectric interfaces, and $(r, z)=(1.02 \mathrm{~mm}, \sim 10.5 \mathrm{~mm})$ at the outer ones. The analysis of the node $\left(E_{z}=0\right)$ and antinode $\left(\left|E_{z}\right|\right.$ peak) of standing waves in Figs. $5(\mathrm{j})$ and $6(\mathrm{~b})$ suggests the quarter-wavelength $\lambda_{\text {sw }} / 4 \approx 7.5-9.5 \mathrm{~mm}$ (between $z \approx 1$ and $10.5 \mathrm{~mm}$ at the outer $r=1.02 \mathrm{~mm}$ and between $z \approx 2$ and $9.5 \mathrm{~mm}$ at the inner $r=0.6 \mathrm{~mm})$, and thus the wavelength $\lambda_{\mathrm{sw}} \approx 30-38 \mathrm{~mm}(\approx \lambda)$.

In addition, simulations for $f=4 \mathrm{GHz}$ with $\mathrm{L}_{\mathrm{s}}=4.5 \mathrm{~mm}$ (case IV, $L_{s} \ll \lambda / 4$ ), not presented here, exhibited contours of plasma and microwave properties that are qualitatively similar to some extent to those in Figs. 5, 6(a), and 6(b) for $f=4 \mathrm{GHz}$ with $\mathrm{L}_{\mathrm{s}}=10.5 \mathrm{~mm}$ (case III), and thus to those in Figs. 2, 3(a), and 3 (b) for $f=11 \mathrm{GHz}$ with $\mathrm{L}_{\mathrm{s}}=4.5 \mathrm{~mm}$ (case I): the plasma electron density $n_{e}$ and temperature $\mathrm{T}_{e}$ exhibit their maxima at one axial position in the plasma source chamber, and the heavy particle temperature $T_{h}$ exhibits its maximum at the end of it; the absorbed power density $Q_{a b s}$ and the field strength $\left|E_{z}\right|$ in the plasma exhibit their peaks at two local positions at the inner and outer plasmadielectric interfaces, and no conspicuous sign reversal or node occurs for $E_{r}$ and $E_{z}$ across the annular plasma region. However, the $\left|E_{z}\right|$ peaks were significantly low for the $f=4 \mathrm{GHz}$ with $\mathrm{L}_{\mathrm{s}}=4.5 \mathrm{~cm}$, which gave a $(\sim 10 \%-40 \%)$ decrease in magnitude of the plasma and microwave absorption properties $\left(n_{e}, \mathrm{~T}_{h}, \mathrm{Q}_{\mathrm{abs}}, n_{*}\right)$, compared with those for $f=4 \mathrm{GHz}$ with $L_{s}=10.5 \mathrm{~mm}$, except the relatively unchanged $\mathrm{T}_{e}, p, u$, and $n_{g}$. The absorbed power was $\mathrm{P}_{\mathrm{abs}} \approx$ $1.5 \mathrm{~W}\left(\mathrm{P}_{\mathrm{abs}} / \mathrm{P}_{\mathrm{in}} \approx 25 \%\right)$, corresponding to the average power density $\overline{\mathrm{Q}}_{\mathrm{abs}}=\mathrm{P}_{\mathrm{abs}} / \mathrm{V} \approx 1.5 \times 10^{8} \mathrm{~W} / \mathrm{m}^{3}$.

Representative values of plasma and microwave properties of interest are compared in Table I, indicating that $f=11 \mathrm{GHz}$ microwaves with $L_{s}=4.5 \mathrm{~mm}$ (case $\mathrm{I}, L_{s} \approx \lambda / 4$ ) give the highest absorbed power density $\mathrm{Q}_{\mathrm{abs}}$ and its spatial average $\bar{Q}_{a b s}$ along with the highest plasma electron density $n_{e}$, heavy particle temperature $\mathrm{T}_{h}$, and metastable density $n_{*}$; it is followed by $f=4 \mathrm{GHz}$ with $\mathrm{L}_{\mathrm{s}}=10.5 \mathrm{~mm}$ (case III, $\left.\mathrm{L}_{\mathrm{s}} \approx \lambda / 4\right)$, $f=11 \mathrm{GHz}$ with $\mathrm{L}_{\mathrm{s}}=10.5 \mathrm{~mm}$ (case II, $\mathrm{L}_{\mathrm{s}} \approx 3 \lambda / 4$ ), and then $f=4 \mathrm{GHz}$ with $\mathrm{L}_{\mathrm{s}}=4.5 \mathrm{~mm}$ (case IV, $\mathrm{L}_{\mathrm{s}} \ll \lambda / 4$ ), where the latter two (cases II and IV) give approximately the same degree of plasma and microwave absorption properties $\left(n_{e}, \mathrm{~T}_{h}\right.$, $\left.\mathrm{Q}_{\mathrm{abs}} / \overline{\mathrm{Q}}_{\mathrm{abs}}, n_{*}\right)$. Note that in these situations, the electron temperature $T_{e}$, pressure $p$, flow velocity $u$, and gas or ground-state density $n_{g}$ remain relatively unchanged for different microwave frequencies $f$ and chamber lengths $L_{s}$. Hence, we conclude that for a given input power $P_{\text {in }}$ and propellant flow rate $\dot{m}$, higher $f$ microwaves with $L_{\mathrm{s}} \approx 1 / 4$ of the driving wavelength $\lambda\left(\approx \lambda_{\mathrm{sw}}\right)$ are preferred for the microplasma thruster, in terms of efficient microwave absorption (higher $\mathrm{Q}_{\mathrm{abs}} / \overline{\mathrm{Q}}_{\mathrm{abs}}$ ), plasma generation (higher $n_{e}$ ), gas heating (higher $\mathrm{T}_{h}$ ), and thus thrust performance (higher $\mathrm{F}_{\mathrm{t}}, \mathrm{I}_{\mathrm{sp}}, \eta_{\mathrm{t}}$, as described later in Sec. II B 4), as well as system compactness (shorter $L_{s}$ ). 
(a) Electron density $n_{e}\left(10^{18} \mathrm{~m}^{-3}\right)$

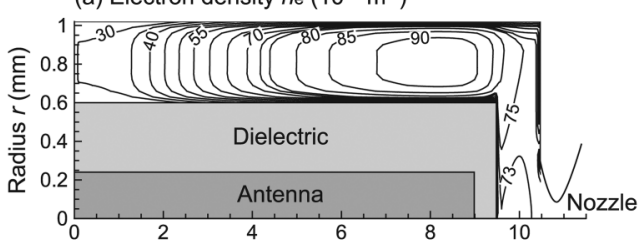

(c) Heavy particle temperature $\mathrm{Th}(\mathrm{K})$

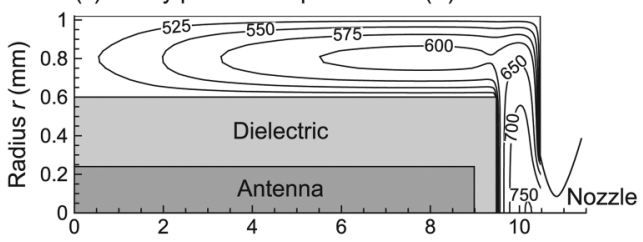

(e) Gas pressure $p(\mathrm{kPa})$

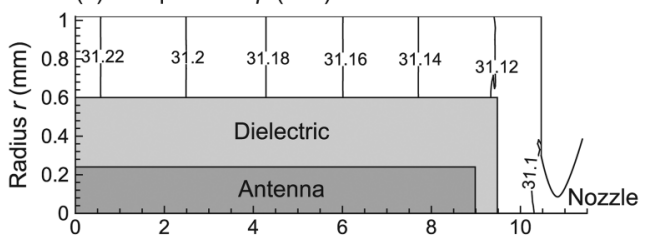

(g) Ground state density $n_{\mathrm{g}}\left(10^{21} \mathrm{~m}^{-3}\right)$

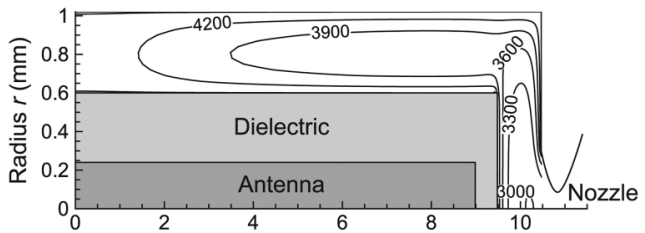

(i) Microwave radial electric field $\operatorname{Er}\left(10^{2} \mathrm{~V} / \mathrm{m}\right)$

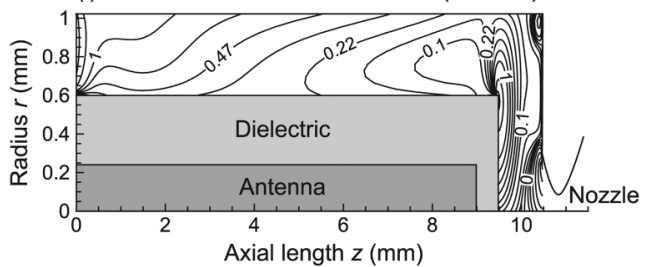

(b) Electron temperature $T_{e}\left(10^{3} \mathrm{~K}\right)$

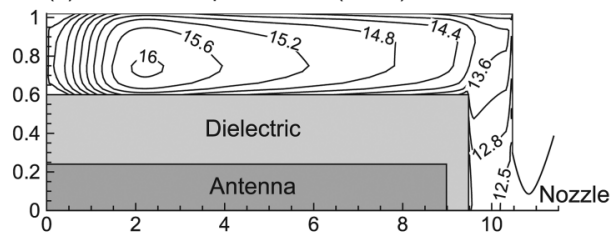

(d) Absorbed power density Qabs $\left(10^{6} \mathrm{~W} / \mathrm{m}^{3}\right)$

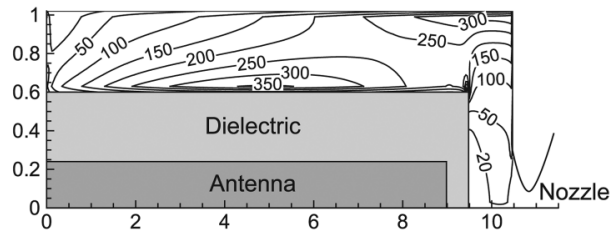

(f) Axial flow velocity $u(\mathrm{~m} / \mathrm{s})$

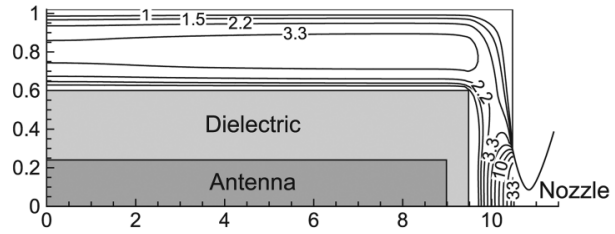

(h) Metastable state density $n_{\star}\left(10^{21} \mathrm{~m}^{-3}\right)$

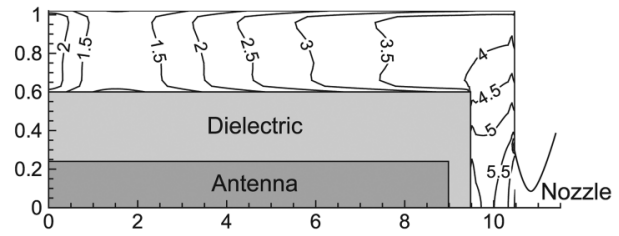

(j) Microwave axial electric field $E_{z}\left(10^{2} \mathrm{~V} / \mathrm{m}\right)$

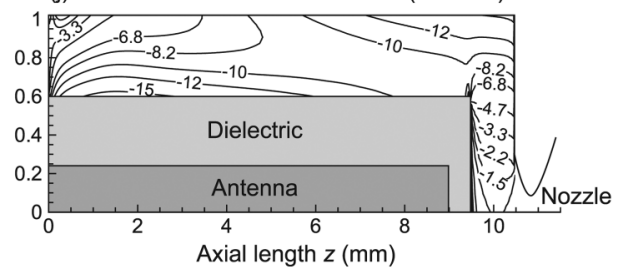

FIG. 5. Distribution of plasma properties in the microplasma source of $L_{s}=10.5 \mathrm{~mm}$, simulated with $f=4 \mathrm{GHz}$ microwaves of $P_{\text {in }}=6.0 \mathrm{~W}$ and an Ar mass flow rate of $\dot{m}=1.5 \mathrm{mg} / \mathrm{s}$ : (a) $n_{e}$, (b) $T_{e}$, (c) $T_{h}$, (d) $Q_{\mathrm{abs}}$, (e) $p$, (f) $u$, (g) $n_{g}\left(\rho \approx m_{h} n_{g}\right)$, and (h) $n_{*}$. Also shown are snapshots of the distribution of microwave electric fields (i) $E_{r}$ and $(j) E_{z}$ in the microplasma source. The figure properties are the same as in the preceding Fig. 4. The microwave power absorbed in the plasma was calculated as $P_{\text {abs }} \approx 4.5 \mathrm{~W}$.

\section{Effects of frequency and chamber dimensions on plasma generation}

Electromagnetic surface waves are assumed to propagate along plasma-dielectric interfaces in overdense plasmas with $n_{e}>n_{\text {cr }}\left[\right.$ or $\left.\omega_{\text {pe }}>\omega\left(1+\varepsilon_{d}\right)^{1 / 2}\right] .{ }^{59-64}$ Here, $n_{\text {cr }}=n_{c}\left(1+\varepsilon_{d}\right)$ denotes the critical density for surface waves (known as the surfacewave resonance density), $n_{c}=\varepsilon_{0} m_{e} \omega^{2} / e^{2}$ the cutoff density for electromagnetic waves of frequency $f=\omega / 2 \pi, \varepsilon_{d}$ the relative permittivity of the dielectric, and $\omega_{\mathrm{pe}}=\left(n_{e} e^{2} / m_{e} \varepsilon_{0}\right)^{1 / 2}$ the plasma electron frequency; moreover, $e$ is the magnitude of electron charge, $m_{e}$ the mass of electron, and $\varepsilon_{0}$ the electric permittivity of vacuum. Thus, higher plasma densities $n_{e}$ are expected for higher frequencies $f$, along with concomitantly higher absorbed powers $\mathrm{Q}_{\mathrm{abs}} / \overline{\mathrm{Q}}_{\mathrm{abs}}$, when surface waves are excited and propagate along the interfaces; the increased $n_{e}$, in turn, leads to higher gas or heavy particle temperatures $T_{h}$ through increased energy transfer via elastic collisions between electrons and heavy particles, which is followed by higher thrust performance. These are consistent with the present simulations in Secs. II B 1 and II B 2, where the cutoff 
(a) Microwave radial electric field $E_{\mathrm{r}}\left(10^{2} \mathrm{~V} / \mathrm{m}\right)$

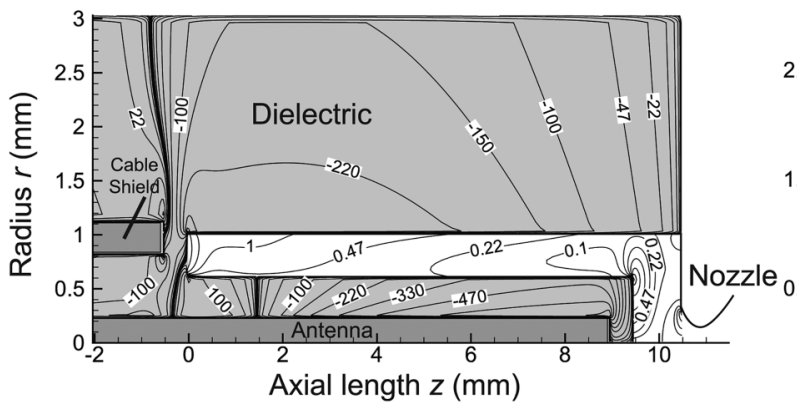

(b) Microwave axial electric field $E_{z}\left(10^{2} \mathrm{~V} / \mathrm{m}\right)$

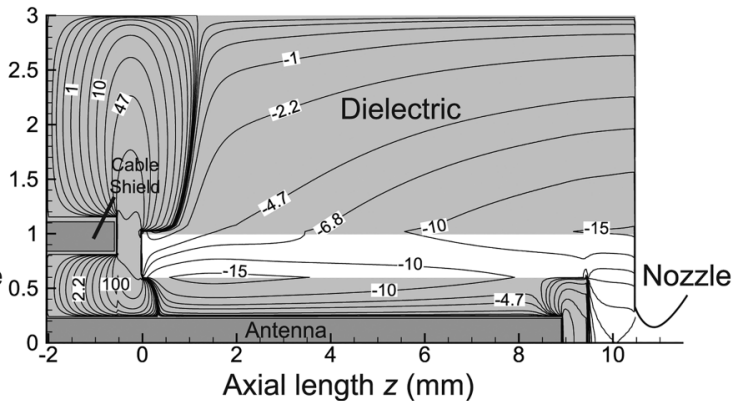

FIG. 6. Extended views of a snapshot of the distribution of microwave electric fields (a) $E_{r}$ and (b) $E_{z}$ in the microplasma source $\left(f=4 \mathrm{GHz}, L_{s}=10.5 \mathrm{~mm}\right)$, corresponding to the preceding Figs. $5(\mathrm{i})$ and $5(\mathrm{j})$. The figure properties are the same as in Figs. 3(c) and 3(d).

and critical densities are $n_{\mathrm{c}}=1.5$ and $0.20 \times 10^{18} \mathrm{~m}^{-3}$ and $n_{\mathrm{cr}}=$ 7.2 and $0.95 \times 10^{18} \mathrm{~m}^{-3}$, respectively, for $f=11$ and $4 \mathrm{GHz}$ microwaves with $\varepsilon_{d}=3.8$, implying that $n_{e}>n_{\mathrm{cr}}>n_{\mathrm{c}}$ with typically $n_{e} \approx(0.62-1.2) \times 10^{20} \mathrm{~m}^{-3}$ (Table I).

Moreover, the present simulations indicated that for a given frequency $f$, the plasma source chamber length $L_{s} \approx \lambda / 4$ $\left(\approx \lambda_{\mathrm{sw}} / 4\right)$ is preferred to achieve higher $\mathrm{Q}_{\mathrm{abs}} / \overline{\mathrm{Q}}_{\mathrm{abs}}, n_{e}$, and $\mathrm{T}_{h}$, where $\lambda$ is the driving wavelength, $\lambda_{\mathrm{sw}}$ is that of surface waves excited, and $L_{s}=4.5$ and $10.5 \mathrm{~mm}$ correspond approximately to $\lambda / 4$ for $f=11$ and $4 \mathrm{GHz}$, respectively. This is attributed to the lowest resonance mode of standing surface waves. In practice, experimental ${ }^{87}$ and theoretical ${ }^{91,92}$ studies of SWPs of planar type indicated that increasing the plasma density (e.g., by increasing the power, by changing the gas pressure,

TABLE I. Comparison of the microplasma generation, micronozzle flow, and thrust performance obtained from numerical simulations for $f=11$ and $4 \mathrm{GHz}$ microwaves of $P_{\text {in }}=6 \mathrm{~W}$ input power with plasma chamber lengths of $L_{s}=4.5$ and $10.5 \mathrm{~mm}$ and an Ar mass flow rate $\dot{m}=1.5 \mathrm{mg} / \mathrm{s}$.

\begin{tabular}{|c|c|c|c|c|c|}
\hline \multirow[b]{2}{*}{ Category } & \multirow[b]{2}{*}{ Property } & \multicolumn{2}{|c|}{$f=11 \mathrm{GHz}$} & \multicolumn{2}{|c|}{$f=4 \mathrm{GHz}$} \\
\hline & & $L_{s}=4.5 \mathrm{~mm}$ (case I) & $L_{s}=10.5 \mathrm{~mm}$ (case II) & $L_{s}=4.5 \mathrm{~mm}$ (case IV) & $L_{s}=10.5 \mathrm{~mm}$ (case III) \\
\hline \multirow[t]{14}{*}{ Plasma generation } & $P_{\text {abs }}(\mathrm{W})$ & 5.1 & 3.5 & 1.5 & 4.5 \\
\hline & $P_{\text {abs }} / P_{\text {in }}(\%)$ & 85 & 58 & 25 & 75 \\
\hline & $V\left(10^{-9} \mathrm{~m}^{3}\right)$ & 10 & 22 & 10 & 22 \\
\hline & $\bar{Q}_{\text {abs }}\left(10^{8} \mathrm{~W} / \mathrm{m}^{3}\right)^{a}$ & 5.0 & 1.6 & 1.5 & 2.0 \\
\hline & $n_{e}\left(10^{20} \mathrm{~m}^{-3}\right)^{b}$ & 1.2 & $0.62-0.65$ & 0.68 & 0.90 \\
\hline & $T_{e}\left(10^{4} \mathrm{~K}\right)^{\mathrm{b}}$ & 1.5 & 1.5 & 1.6 & 1.6 \\
\hline & $T_{h}(\mathrm{~K})^{\mathrm{c}}$ & 950 & 700 & 700 & 750 \\
\hline & $Q_{a b s}\left(10^{8} \mathrm{~W} / \mathrm{m}^{3}\right)^{\mathrm{d}}$ & $10-12$ & $3.0-3.5$ & 2.0 & $3.0-3.5$ \\
\hline & $p(\mathrm{kPa})^{\mathrm{c}}$ & 35 & 31 & 31 & 31 \\
\hline & $u(\mathrm{~m} / \mathrm{s})^{c}$ & 33 & 33 & 33 & 33 \\
\hline & $n_{g}\left(10^{24} \mathrm{~m}^{-3}\right)^{b}$ & 4.5 & 4.2 & 4.2 & 4.2 \\
\hline & $n_{*}\left(10^{21} \mathrm{~m}^{-3}\right)^{\mathrm{b}}$ & 6.5 & 5.0 & 4.0 & 5.5 \\
\hline & $\left|E_{r}\right|\left(10^{2} \mathrm{~V} / \mathrm{m}\right)^{\mathrm{e}}$ & 2.2 & 2.2 & 1.5 & 1.0 \\
\hline & $\left|E_{z}\right|\left(10^{2} \mathrm{~V} / \mathrm{m}\right)^{e}$ & $22-25$ & $15-22$ & 4.7 & $12-15$ \\
\hline \multirow{4}{*}{ Nozzle flow } & $T_{h}(\mathrm{~K})^{f}$ & 250 & 200 & 200 & 200 \\
\hline & $M a^{f^{\prime}}$ & 3.2 & 3.2 & 3.2 & 3.2 \\
\hline & $p(\mathrm{kPa})^{f}$ & 0.7 & 0.5 & 0.5 & 0.5 \\
\hline & $u(\mathrm{~m} / \mathrm{s})^{f}$ & 800 & 700 & 700 & 750 \\
\hline \multirow[t]{4}{*}{ Thrust performance } & $F_{t}(\mathrm{mN})$ & 1.2 & 1.0 & 1.0 & 1.1 \\
\hline & $l_{\mathrm{sp}}(\mathrm{s})$ & 85 & 71 & 71 & 77 \\
\hline & $\eta_{t}(\%)$ & 8.3 & 5.8 & 5.8 & 6.9 \\
\hline & $F_{t 0}(\mathrm{mN})$ & 0.77 & 0.77 & 0.77 & 0.77 \\
\hline
\end{tabular}

${ }^{\mathrm{a}} \bar{Q}_{\mathrm{abs}}=P_{\mathrm{abs}} / \mathrm{V}$.

${ }^{b}$ Maximum value(s) in the plasma source.

${ }^{c}$ At the end of the plasma source on the axis (or, at the inlet of the nozzle on the axis).

${ }^{\mathrm{d}}$ Maximum value(s) at inner and outer plasma-dielectric interfaces in the plasma source.

${ }^{\mathrm{e} M a x i m u m}$ instantaneous value(s) at inner and outer plasma-dielectric interfaces in the plasma source.

${ }^{\mathrm{f}}$ At the exit of the nozzle on the axis. 
or by doing both), the microwave field pattern of standing surface waves changes to lower and lower modes, which may also apply to linear SWPs because the latter ${ }^{91,92}$ are not limited to any particular geometry; note that there are few known studies concerned with resonant standing wave modes for linear SWPs, to the best of our knowledge, since most studies of them have been concerned with long plasma columns where traveling surface waves are launched along plasma-dielectric interfaces. ${ }^{59-62,88-90,93-96}$ Thus, higher plasma densities $n_{e}$ are also expected for the geometry of $\mathrm{L}_{\mathrm{s}} \approx \lambda / 4\left(\approx \lambda_{\mathrm{sw}} / 4\right)$ that would give the lowest mode of resonance, along with concomitantly increased $\mathrm{Q}_{\mathrm{abs}} / \overline{\mathrm{Q}}_{\mathrm{abs}}$, when standing surface waves are excited and sustained along the interfaces; then, the increase in $n_{e}$ leads to higher temperatures $\mathrm{T}_{h}$ through increased energy transfer via electron-neutral elastic collisions, and to higher thrust performance.

Additionally, the preferred length $L_{s} \approx \lambda / 4$ may partly reflect the condition of the so-called resonant monopole or cylindrical dipole antenna for microwaves ${ }^{97}$ (the present antenna length is taken to be $L_{a n}=L_{s}-0.9 \mathrm{~mm}=3.6$ and $9.6 \mathrm{~mm}$ for $L_{\mathrm{s}}=4.5$ and $10.5 \mathrm{~mm}$, respectively, as in Sec. II A); this is an issue remaining unresolved at the present stage, which will require further numerical studies of the system without plasma, along with those to investigate effects of different $L_{a n}$ for a given $L_{s}$.

It is further noted that in SWPs, the microwaves are assumed to penetrate into the plasma along plasma-dielectric interfaces even in the overdense mode to heat plasma electrons in a thin skin-depth layer. ${ }^{59-64}$ The skin depth is estimated to be $\delta_{\mathrm{c}} \approx(1.4-1.8)$ and (2.5-2.9) $\mathrm{mm}$ (increasing with decreasing $n_{e}$, and with increasing $T_{e}$ and $n_{g}$ ) for $f=11$ and $4 \mathrm{GHz}$, respectively, under the present plasma conditions [typically $n_{e} \approx(0.62-1.2) \times 10^{20} \mathrm{~m}^{-3}, \mathrm{~T}_{e} \approx(1.5-1.6) \times 10^{4} \mathrm{~K}$, and $n_{g} \approx(4.2-4.5) \times 10^{24} \mathrm{~m}^{-3}$ as in Table I]. Here, $\delta_{\mathrm{c}}=\delta\left(2 v_{m} / \omega\right)^{1 / 2}$ is the collisional skin depth (for $\left.v_{m} \gg \omega\right)$, ${ }^{64} \delta=c / \omega_{\text {pe }}$ the collisionless skin depth, and $v_{m}$ the electron-neutral (Ar) momentum transfer collision frequency; the parameters concerned here are $\omega_{\mathrm{pe}} \approx(4.4-6.2) \times 10^{11} \mathrm{rad} / \mathrm{s}$ (increasing with increasing $\left.n_{e}\right), \delta=c / \omega_{\mathrm{pe}} \approx 0.48-0.68 \mathrm{~mm}$ (increasing with decreasing $n_{e}$ ), $v_{m} \approx(2.5-2.7) \times 10^{11} \mathrm{~s}^{-1}$ (increasing with increasing $\mathrm{T}_{e}$ and $\left.n_{g}\right){ }^{98}$ and $\omega=2 \pi f=2.5$ and $6.9 \times 10^{10} \mathrm{rad} / \mathrm{s}$ for $f=4$ and $11 \mathrm{GHz}$, respectively. Thus, the skin depth is comparable to or a little larger than the characteristic radial (or lateral) dimension of the annular plasma region presently concerned, $\delta_{c}>R_{c}=\left(d_{s, \text { in }}-d_{d, \text { out }}\right) / 2=0.42 \mathrm{~mm}$, in which the surface waves can be assumed to be established and propagate along the inner and outer interfaces and the microwaves are then absorbed to heat plasma electrons. If the lateral dimension of the plasma source was reduced to $R_{c} \ll \delta_{c}$, the region of microwave absorption would be reduced, and thus the plasma generation, gas heating, and thrust performance would be deteriorated. On the other hand, if it was increased to $R_{c} \gg \delta_{c}$, the size and weight of the system would be increased, though the region of microwave absorption along the interfaces would remain relatively unchanged and correspondingly the plasma generation, gas heating, and thrust performance would not be deteriorated.

\section{Micronozzle flow and thrust performance}

Figures $7(\mathrm{a})-7(\mathrm{~h})$ show the distribution of the electron density $n_{e}$, electron temperature $\mathrm{T}_{e}$, heavy particle temperature $\mathrm{T}_{h}$, Mach number $\mathrm{Ma}=|\boldsymbol{v}| / a$, pressure $p$, axial flow velocity $u$, Ar gas or ground-state density $n_{g}$, and Ar* metastable-state density $n_{*}$ in the micronozzle, respectively, obtained in simulations of Fig. 2 for $f=11 \mathrm{GHz}$ with $\mathrm{L}_{\mathrm{s}}=4.5 \mathrm{~mm}$ (case I). Here, $a=\sqrt{\gamma \mathrm{RT}_{h}}$ is the sonic speed in Ar, $\gamma=5 / 3$ denotes the specific heat ratio for monoatomic gases, and $R=k_{B} / m_{h}$ the gas constant. The temperature $\mathrm{T}_{h}$, Mach number $M a$, pressure $p$, flow velocity $u$, and gas $n_{g}$ and metastable $n_{*}$ densities exhibit a characteristic of the subsonic-supersonic or aerodynamic acceleration of the flow in the converging-diverging nozzle: $M a$ and $u$ increase with increasing axial distance, with $M a=1$ being at around the throat, while $\mathrm{T}_{h}, p, n_{g}$, and $n_{*}$ decrease downstream along the nozzle axis $\left(\mathrm{T}_{h} \approx 250 \mathrm{~K}, \mathrm{Ma} \approx 3.2, p \approx 0.7\right.$ $\mathrm{kPa}$, and $u \approx 800 \mathrm{~m} / \mathrm{s}$ at the nozzle exit on the axis). However, the contour of $\mathrm{T}_{h}, \mathrm{Ma}$, and $u$ indicates that the boundary layers associated with viscosity are relatively thick in the micronozzle, especially in the divergent or supersonic portion of the nozzle. ${ }^{50,53,56,57}$ In practice, the Mach number $\mathrm{Ma}$ and flow velocity $u$ are lower and the temperature $T_{h}$ is higher closer to the nozzle walls in the diverging portion; and the flow therein is supersonic $(\mathrm{M} a>1)$ around the nozzle axis, while subsonic $(M a<1)$ near the walls over roughly half of the nozzle cross section. Thus, the nozzle flow tends to be underexpanded, or the supersonic expansion of the flow is suppressed in the diverging portion, giving the nozzle outlet velocity lower than its maximum theoretical value that should be reached with an infinite expansion (exhausting into vacuum, as mentioned later in Sec. III C): ${ }^{99,100} u_{\infty}=\sqrt{2 \gamma \mathrm{RT}_{0} /(\gamma-1)}$ $\approx 990 \mathrm{~m} / \mathrm{s}$, assuming the stagnation temperature $\mathrm{T}_{0}=\mathrm{T}_{h} \approx 950 \mathrm{~K}$ at the nozzle inlet [Fig. 2(c)]. Note that the decrease of the temperature $T_{h}$ along the nozzle axis is not so significant as compared to the change of the other flow properties $\left(n_{e}, \mathrm{Ma}\right.$, $\left.p, u, n_{g}, n_{*}\right)$ except for $\mathrm{T}_{e}$, owing to heating due to viscous dissipation in thick boundary layers; moreover, the electron temperature $\mathrm{T}_{e}$ exhibits no significant decrease along the axis, owing to the energy gained by plasma electrons through inelastic processes of electron-impact deexcitation and electron-ion recombination during expansion.

The thrust performance is calculated from the flow properties at the nozzle exit, ${ }^{100}$

$$
\begin{gathered}
F_{t}=2 \pi \int_{0}^{r_{e x}}\left(\rho u^{2}+p\right) r d r, \\
I_{\mathrm{sp}}=\frac{F_{t}}{\dot{m} g} \\
\eta_{t}=\frac{F_{t}^{2}}{2 \dot{m} P_{\text {in }}+F_{t 0}^{2}},
\end{gathered}
$$

where $F_{t}$ is the thrust, $I_{s p}$ the specific impulse, and $\eta_{t}$ the thrust efficiency. In these equations, $r_{\mathrm{ex}}$ denotes the exit 

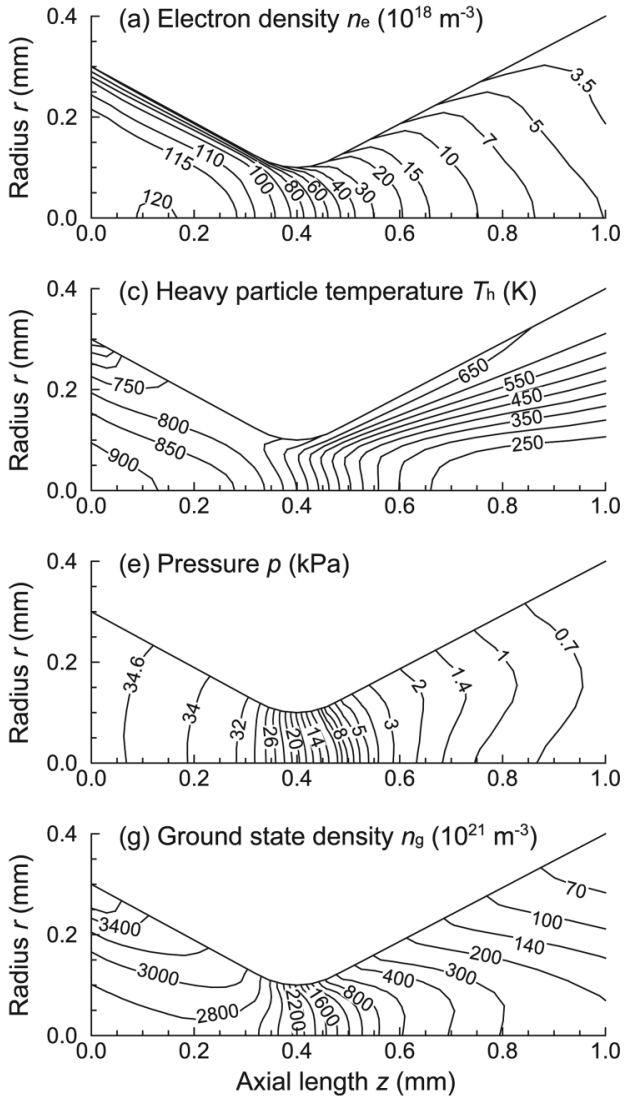
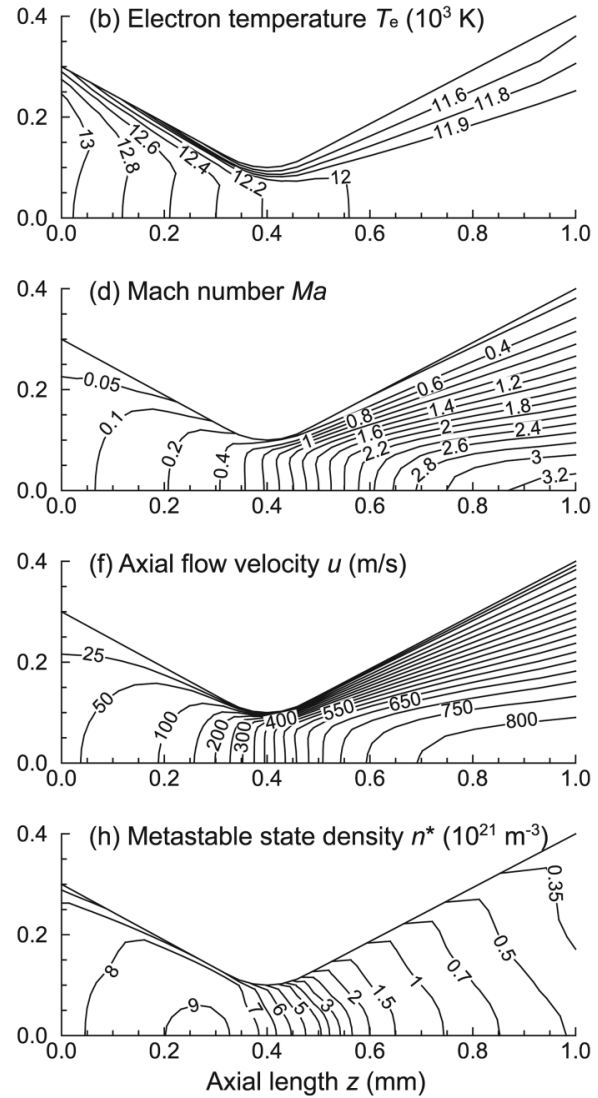

FIG. 7. Distribution of plasma flow properties in the micronozzle, obtained in numerical simulations of Fig. $2\left(f=11 \mathrm{GHz}, P_{\text {in }}=6.0 \mathrm{~W}, L_{s}=4.5 \mathrm{~cm}, \dot{m}=1.5 \mathrm{mg} / \mathrm{s}\right):(a) n_{e}$, (b) $T_{e}$, (c) $T_{h}$, (d) $M a$, (e) $p$, (f) $u$, (g) $n_{g}\left(\rho \approx m_{h} n_{g}\right)$, and (h) $n_{*}$. The nozzle has an inlet, throat, and exit diameter of $d_{\text {in }}=0.6 \mathrm{~mm}, d_{\mathrm{th}}=0.2 \mathrm{~mm}$, and $d_{\mathrm{ex}}=0.8 \mathrm{~mm}$, respectively, with a diverging angle of $\theta=26.6^{\circ}$ and a total length of $1 \mathrm{~mm}$.

radius of the nozzle, $\rho$ the mass density, $u$ the exhaust flow velocity in the axial direction, $p$ the pressure, $\dot{m}=$ $2 \pi \int_{0}^{r_{\text {ex }}}$ pur $d r$ the mass flow rate, $g$ the gravitational constant, and $F_{t 0}$ the thrust in cold gas operation without plasma discharge. Note that $I_{s p}$ and $\eta_{t}$ scale with $F_{t}$ for a given input power $P_{\text {in }}$ and propellant flow rate $\dot{m}$, and that $F_{t}$ consists of the momentum and pressure thrust. The pressure thrust is often neglected owing to its less contribution to the total thrust; however, reducing the size of the nozzle results in underexpanded gas/plasma flows inside the nozzle owing to highly viscous flows therein, as mentioned above, and so the pressure thrust should be taken into account in the present microplasma thruster. ${ }^{50,53,56,57}$ The thrust performance calculated from nozzle flow properties of Fig. 7 is $F_{t} \approx 1.2 \mathrm{mN}$, $\mathrm{I}_{\mathrm{sp}} \approx 85 \mathrm{~s}$, and $\eta_{\mathrm{t}} \approx 8.3 \%$.

Similar contours of nozzle flow properties, not presented here, were obtained in simulations of Fig. 4 for $f=11 \mathrm{GHz}$ with $L_{\mathrm{s}}=10.5 \mathrm{~mm}$ (case II), simulations of Fig. 5 for $f=4 \mathrm{GHz}$ with $L_{\mathrm{s}}=10.5 \mathrm{~mm}$ (case III), and simulations for $f=4 \mathrm{GHz}$ with $L_{\mathrm{s}}=4.5 \mathrm{~mm}$ (case IV). However, compared with Fig. 7 for $f=11 \mathrm{GHz}$ with $\mathrm{L}_{\mathrm{s}}=4.5 \mathrm{~mm}$ (case I), the aerodynamic acceleration of the flow (or the increase of the axial flow velocity $u$ ) in the nozzle and thus the thrust performance was reduced in the order of case I, III, II, and IV, owing primarily to the temperature $\mathrm{T}_{h}$ at around the end of the plasma source (or at the nozzle inlet) that is lowered in this order. In effect the heavy particle temperature, Mach number, pressure, and flow velocity at the nozzle exit on the axis were $T_{h} \approx 200 \mathrm{~K}$, $\mathrm{M} a \approx 3.2, \quad p \approx 0.5 \mathrm{kPa}$, and $u \approx 700 \mathrm{~m} / \mathrm{s}$ for $f=11 \mathrm{GHz}$ and $\mathrm{L}_{\mathrm{s}}=10.5 \mathrm{~mm}$ (case II) and $\mathrm{T}_{h} \approx 200 \mathrm{~K}, \mathrm{Ma} \approx 3.2, p \approx 0.5 \mathrm{kPa}$, and $u \approx 750 \mathrm{~m} / \mathrm{s}$ for $f=4 \mathrm{GHz}$ with $\mathrm{L}_{\mathrm{s}}=10.5 \mathrm{~mm}$ (case III), respectively. Correspondingly, the thrust performance was calculated to be $\mathrm{F}_{\mathrm{t}} \approx 1.0 \mathrm{mN}, \mathrm{I}_{\mathrm{sp}} \approx 71 \mathrm{~s}$, and $\eta_{\mathrm{t}} \approx 5.8 \%$ for the case II and $\mathrm{F}_{\mathrm{t}} \approx 1.1 \mathrm{mN}, \mathrm{I}_{\mathrm{sp}} \approx 77 \mathrm{~s}$, and $\eta_{\mathrm{t}} \approx 6.9 \%$ for the case III. Representative values of the nozzle flow properties of interest are also compared in Table I, along with those of the thrust performance, indicating that $f=11 \mathrm{GHz}$ with $\mathrm{L}_{\mathrm{s}}=4.5 \mathrm{~mm}$ (case I) gives the highest flow velocity $u$ at the nozzle exit and thrust performance $\left(F_{t}, I_{s p}, \eta_{t}\right)$, which are $\sim 10 \%$ higher than those for the following $f=4 \mathrm{GHz}$ with $\mathrm{L}_{\mathrm{s}}=10.5 \mathrm{~mm}$ (case III). 
Figure 8 shows the plasma electron density $n_{e}$, gas or heavy particle temperature $\mathrm{T}_{h}$, average absorbed power density $\bar{Q}_{\mathrm{abs}}$, and specific impulse $\mathrm{I}_{\mathrm{sp}}$ as a function of plasma chamber length in the range $L_{s}=3-12 \mathrm{~mm}$, simulated for $f=11$ and $4 \mathrm{GHz}$ microwaves with an input power $P_{\text {in }}=6 \mathrm{~W}$ and an Ar mass flow rate $\dot{m}=0.9 \mathrm{mg} / \mathrm{s}$ (a flow rate of $30 \mathrm{sccm}$ ). Here, $n_{e}$ and $T_{h}$ are their maximum values in the microplasma source, and $\bar{Q}_{a b s}$ is the spatial average of $\mathrm{Q}_{\mathrm{abs}}$ therein; the maximum $T_{h}$ concerned here occurs in a space at the end of the plasma source chamber (or just upstream of the nozzle inlet, as mentioned in Secs. II B 1 and II B 2 with respect to Figs. 2, 4, and 5). The simulations indicate that the thrust performance $\left(\mathrm{I}_{\mathrm{sp}}\right)$ tends to peak at $\mathrm{L}_{\mathrm{s}}=4$ and $8 \mathrm{~cm}[\approx \lambda / 4$ and $\lambda / 2$, respectively, with $\left.\lambda \approx 14 \mathrm{~mm}\left(\approx \lambda_{\mathrm{sw}}\right)\right]$ for $f=11 \mathrm{GHz}$ and to slightly peak at $L_{\mathrm{s}}=10 \mathrm{~cm}\left[\approx \lambda / 4\right.$ with $\left.\lambda \approx 38 \mathrm{~mm}\left(\approx \lambda_{\mathrm{sw}}\right)\right]$ for $f=4 \mathrm{GHz}$, and that the peak for $f=11 \mathrm{GHz}$ tends to be higher at $\mathrm{L}_{\mathrm{s}}=4 \mathrm{~mm}$ than at $\mathrm{L}_{\mathrm{s}}=8 \mathrm{~mm}$. Moreover, the $n_{e}, \mathrm{~T}_{h}$, and $\overline{\mathrm{Q}}_{\mathrm{abs}}$ exhibit $L_{s}$ dependences similar to that of $I_{s p}$, which would be no wonder, since the microwave energy is assumed to be absorbed to heat plasma electrons, and then to be transferred to heavy particles through elastic and inelastic collisions between electrons and heavy particles (as mentioned earlier in Sec. II A). Hence, we can totally conclude that for a given $P_{\text {in }}$ and $\dot{m}$, higher $f$ microwaves with $L_{s} \approx 1 / 4$ of the driving wavelength $\lambda\left(\approx \lambda_{\mathrm{sw}}\right)$, which correspond to the lowest resonance mode of standing surface waves, are preferred for higher thrust performance and system compactness, resulting
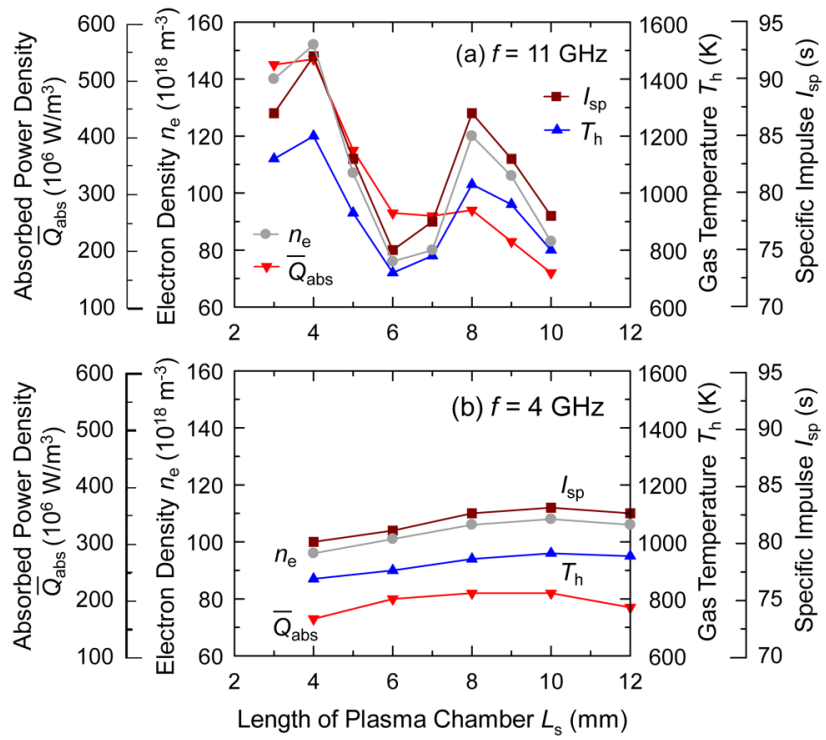

FIG. 8. Plasma electron density $n_{e}$, gas or heavy particle temperature $T_{h}$, average absorbed power density $\bar{Q}_{\mathrm{abs}}$, and specific impulse $I_{\mathrm{sp}}$ as a function of the plasma chamber length in the range $L_{s}=3-12 \mathrm{~mm}$, simulated for $f=$ (a) 11 and (b) $4 \mathrm{GHz}$ microwaves of $P_{\text {in }}=6 \mathrm{~W}$ with an $\mathrm{Ar}$ mass flow rate of $\dot{m}=0.9 \mathrm{mg} / \mathrm{s}$. Here, the dimensions of the microplasma source and micronozzle are the same as in Figs. 2-7, with the antenna envelope and antenna lengths being $L_{d}=L_{s}-1.0 \mathrm{~mm}$ and $L_{\mathrm{an}}=L_{s}-0.9 \mathrm{~mm}$. from more efficient microwave absorption (higher $\mathrm{Q}_{\mathrm{abs}} / \overline{\mathrm{Q}}_{\mathrm{abs}}$ ), plasma generation (higher $n_{e}$ ), and gas heating (higher $T_{h}$ ). In practice, the temperature $T_{h}$ should be a direct or the most sensitive measure of the thrust performance, because it is expected to be increased with increasing the source or stagnation temperature $\mathrm{T}_{0}=\mathrm{T}_{h}$ for a given $\mathrm{P}_{\text {in }}$ and $\dot{m}$ (as described later in Sec. III C).

\section{EXPERIMENT}

\section{A. Experimental setup}

Figure 9 shows a schematic of the microplasma thruster in experiments of this study, which was designed to generate microplasmas with both X-band and S-band microwaves; in practice, plasma discharges with $f=11 \mathrm{GHz}$ microwaves could not be established in preliminary experiments using the previous model for $f=4 \mathrm{GHz},{ }^{56,57}$ where $f=11 \mathrm{GHz}$ discharges occurred at around the root or feedpoint of the antenna, not in the entire region of the plasma source chamber. Thus, in this study, the dielectric envelope of the antenna was redesigned and fabricated with smooth steps at around its feedpoint; moreover, the micronozzle at the end of the plasma source was fabricated integrally with the dielectric source chamber to resolve mechanical issues. As compared with the previous configuration, ${ }^{56,57}$ the present design has about a factor of two larger diameter of the microplasma source and larger volume of the plasma discharge region (its surface area-to-volume ratio remains relatively unchanged), while the dimensions of the micronozzle remain the same as those of the previous one.

The microplasma source and micronozzle in Fig. 9 are similar in size to those of the numerical model as in Figs. 2-8. The plasma source chamber made of quartz $\left(\varepsilon_{d}=3.8\right)$ has a length $L_{s}$, being $d_{s, i n}=2.0 \mathrm{~mm}$ in the inner diameter and $d_{\mathrm{s}, \text { out }}=6.0 \mathrm{~mm}$ in the outer diameter. The $0.5-\mathrm{mm}$-diam center conductor of a semirigid coaxial cable (RG-405/U), protruding

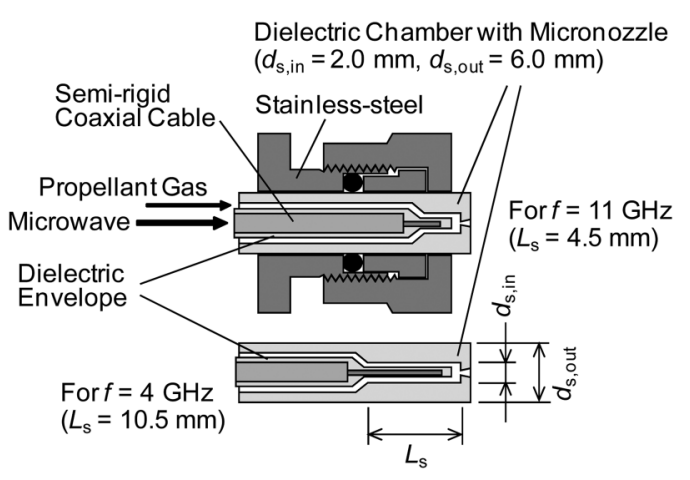

FIG. 9. Schematic of the microplasma thruster in experiments. The microplasma source and micronozzle are similar in size to those of the numerical model as in Figs. 2-8; the plasma chamber length in experiments is taken to be $L_{s}=4.5 \mathrm{~mm}$ for $f=11$ microwaves [corresponding to Figs. 2, 3(a), and $3(b)$ ], while it is to be $L_{s}=10.5 \mathrm{~mm}$ for $f=4 \mathrm{GHz}$ ones (corresponding to Figs. 5 and 6). 
a length of $\sim \mathrm{L}_{\mathrm{an}}$ beyond the insulator (PTFE, $\varepsilon_{i}=2.1$ ) and outer conductor (2.2-mm-diam metallic shield), is covered with a quartz envelope, which is inserted in the source chamber as a microwave rod antenna. The antenna envelope of quartz has a length $L_{d}$, being $d_{d, \text { in }}=0.5 \mathrm{~mm}\left(=d_{\mathrm{an}}\right)$ in the inner diameter and $d_{d, \text { out }}=1.2 \mathrm{~mm}$ in the outer diameter, and an annular spacing is retained between the plasma chamber and antenna envelope $\left[R_{c}=\left(d_{s, \text { in }}-d_{d, \text { out }}\right) / 2=0.4 \mathrm{~mm}\right]$ for feeding propellant gases. The lengths of the plasma source in experiments are taken to be $L_{s}=4.5 \mathrm{~mm}, L_{d}=3.5 \mathrm{~mm}$, and $L_{a n}=3.6 \mathrm{~mm}$ for $f=11 \mathrm{GHz}$ microwaves [corresponding to Figs. 2, 3(a), and 3(b) in Sec. II B 1 (case I, $L_{s} \approx \lambda / 4$ )], while they are to be $L_{s}=10.5 \mathrm{~mm}, L_{d}=9.5 \mathrm{~mm}$, and $L_{\text {an }}=9.6 \mathrm{~mm}$ for $f=4 \mathrm{GHz}$ [corresponding to Figs. 5 and 6 in Sec. II B 2 (case III, $L_{s} \approx \lambda / 4$ )]. Note that in figures of Sec. II B, a part $(L=3$ or $9 \mathrm{~mm})$ of the antenna length $L_{\mathrm{an}}$ is seen in Figs. 2, 4, and 5 , while the length $L_{a n}$ is seen totally in extended views of Figs. 3 and 6. In addition, the micronozzle of converging-diverging type is $1 \mathrm{~mm}$ long, having an inlet, throat, and exit diameter of $d_{\text {in }}=0.6 \mathrm{~mm}, d_{\mathrm{th}}=0.2 \mathrm{~mm}$, and $d_{\mathrm{ex}}=0.8 \mathrm{~mm}$, respectively. The plasma source chamber integrated with the antenna and micronozzle are inserted into a stainless-steel housing to cover the microplasma source with a metal grounded. The microplasma thruster thus configured was set in a vacuum chamber, which was pumped down to $<1 \times 10^{-4} \mathrm{~Pa}$ by a dry and turbomolecular pump prior to experiments.

Microwave signals of $f=11$ and $4 \mathrm{GHz}$ from a signal generator (Agilent E8257C, $250 \mathrm{kHz}-20 \mathrm{GHz}$ ) were amplified through the respective four-stage semiconductor amplifiers to powers of nominally $\mathrm{P}_{\text {in }} \leq 6 \mathrm{~W}$ and then fed into the microplasma source through a flexible low-loss microwave coaxial cable. Here, a miniature triple-stub tuner (Maury Microwave 1819C, 2.0-18.0 $\mathrm{GHz}$ ) was used to suppress the reflection of microwaves. The microwave input power $P_{\text {in }}$ was measured at the entrance of the microplasma source (or at the end of the microwave cable), using a power meter (HP 437B/8481A, $10 \mathrm{MHz}-18 \mathrm{GHz}$ ) with a 30- $\mathrm{dB}$ attenuator. In addition, the spectrum of microwaves was measured with and without plasma discharge, using a spectrum analyzer (Agilent E4408B, $9 \mathrm{kHz}-26.5 \mathrm{GHz}$ ) with a small singleturn magnetic loop coil antenna placed downstream of the end of the source chamber; then, the spectrum exhibited a fundamental peak at $f=11$ and $4 \mathrm{GHz}$ with the respective harmonics, whose intensities were lowered with increasing harmonic order and increased with the plasma discharge turned on (possibly similar to the results of recent Ref. 101).

The propellant or working gas Ar was supplied through a mass flow controller; in some cases, a small amount $(<1 \%)$ of $\mathrm{N}_{2}$ and $\mathrm{H}_{2}$ was added for plasma diagnostics. The stagnation pressure $p_{0}\left(=p \approx n_{g} k_{\mathrm{B}} \mathrm{T}_{h}\right)$ in the microplasma source was measured by a pressure gauge set upstream of the source chamber. The gas flow rate (or mass flow rate $\dot{m}$ ) and the source pressure $p_{0}$ measured with and without plasma discharge were approximately related by ${ }^{99,100}$

$$
\dot{m}=\rho u A=p_{0} A^{*}\left[\frac{\gamma}{\mathrm{RT}_{0}}\left(\frac{2}{\gamma+1}\right)^{(\gamma+1) /(\gamma-1)}\right]^{1 / 2}
$$

where the quasi-one-dimensional isentropic flow of perfect gases in a converging-diverging nozzle, ${ }^{99,100}$

$$
u=\left[\frac{2 \gamma}{\gamma-1} \mathrm{RT}_{0}\left\{1-\left(p / p_{0}\right)^{(\gamma-1) / \gamma}\right\}\right]^{1 / 2}
$$

is assumed along with the so-called choked flow condition $(M a=1)$ at the throat, ${ }^{99,100} \mathrm{~A}$ is the nozzle cross section, $\mathrm{A}^{*}$ is that at the throat, and $\mathrm{T}_{0}\left(=\mathrm{T}_{h}\right)$ is the source or stagnation temperature. In practice, the temperature $T_{0}$ was taken to be the gas temperature spectroscopically measured in plasma discharge operation and to be the room temperature in cold gas operation, indicating that the pressure was approximately proportional to the Ar flow rate in the range $10-70 \mathrm{sccm}$ $(\dot{m}=0.3-2.1 \mathrm{mg} / \mathrm{s}) ;{ }^{56}$ e.g., $p_{0} \approx 5.5-40 \mathrm{kPa}$ in the former with $f=11 \mathrm{GHz}$ microwaves of $\mathrm{P}_{\text {in }}=6 \mathrm{~W}$, and $p_{0} \approx 2.5-22 \mathrm{kPa}$ in the latter with $P_{\text {in }}=0 \mathrm{~W}$. The background pressure in the vacuum chamber was $p_{b} \approx 0.1-0.2 \mathrm{kPa}$ under thruster operation $\left(p_{0} / p_{b}>25\right)$.

To characterize the microplasma generated, optical emissions from the plasma were observed in the side-view direction through a 1-mm-diameter small hole of the stainless-steel housing at around the end of the antenna envelope (or just upstream of the nozzle inlet). ${ }^{56}$ Two spectrographs/spectrometers were employed in these experiments: a $10-\mathrm{cm}$ focal length one (Ocean Optics HR2000CG-UV-NIR) equipped with a grating of 300 lines $/ \mathrm{mm}$, having a linear charge-coupled device (CCD; $1 \times 2048$ pixels, $0.2 \times 28.6 \mathrm{~mm}^{2}$ ) detector; and a $50-\mathrm{cm}$ focal length one (Acton SpectraPro 2500i) equipped with a grating of 2400 lines $/ \mathrm{mm}$, having a CCD detector (Princeton PI-MAX1K; $1024 \times 1024$ pixels, $13.3 \times 13.3 \mathrm{~mm}^{2}$ ) and a photomultiplier (Hamamatsu R2949). A set of quartz lenses were used to collect the emissions from the plasma and focus them onto the entrance slit of the spectrometer. The spectral resolution, determined using a low-pressure Ar discharge lamp, was 1.0 and $0.025 \mathrm{~nm}$ for the $10-$ and $50-\mathrm{cm}$ spectrometer, respectively, with an entrance slit width of $5 \mu \mathrm{m}$. In addition, a Langmuir probe was located in the plasma jet plume downstream of the nozzle exit to measure the plasma electron density therein, ${ }^{52}$ where the probe was cylindrical with a tungsten rod $0.05 \mathrm{~mm}$ in diameter and $0.5 \mathrm{~mm}$ long.

\section{B. Plasma characteristics}

Figure 10 shows a typical optical emission spectrum in the wavelength range $200-900 \mathrm{~nm}$ of the microplasma, observed in plasma discharge operation with $f=11$ and $4 \mathrm{GHz}$ microwaves of $P_{\text {in }}=6 \mathrm{~W}$ and an Ar flow rate of $10 \mathrm{sccm}$ $(\dot{m}=0.3 \mathrm{mg} / \mathrm{s})$. The inset is the spectrum magnified in the visible $400-460 \mathrm{~nm}$. The spectrum consists of intense and weak Ar I (Ar neutral) lines in the near-ir and visible region, respectively, ${ }^{102}$ where no $\mathrm{Ar}$ II $\left(\mathrm{Ar}^{+}\right.$ion) lines were identified in the present experiments. In addition, the spectrum contains atomic lines and molecular bands originating probably from traces of water vapor (adsorbed on walls of the microplasma source chamber and the antenna envelope) and from 
(a) $f=11 \mathrm{GHz}$

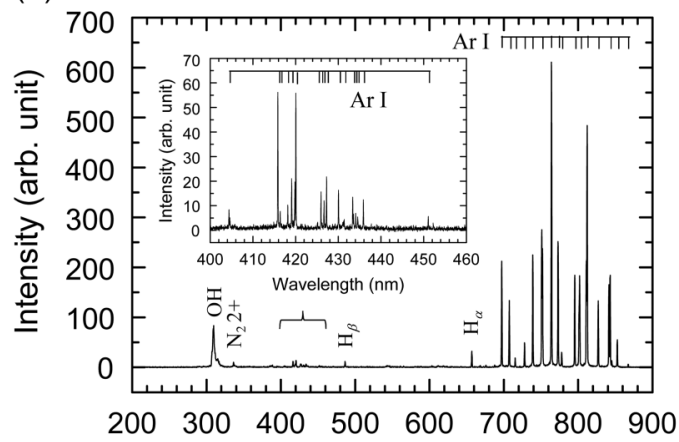

(b) $f=4 \mathrm{GHz} \quad$ Wavelength $(\mathrm{nm})$

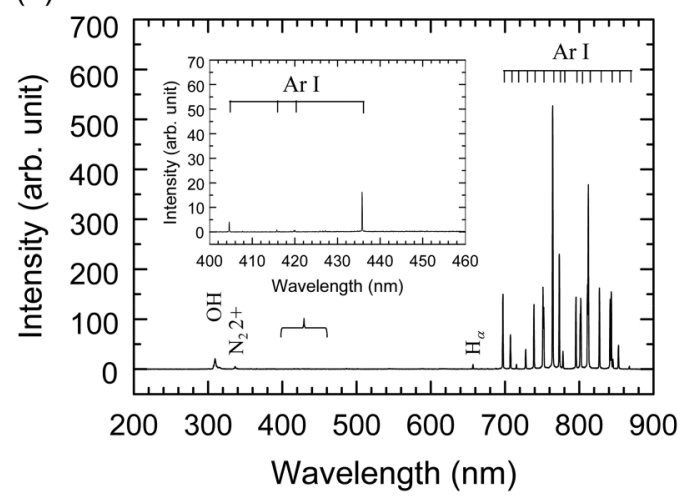

FIG. 10. Typical optical emission spectrum in the wavelength range $200-900 \mathrm{~nm}$ of the microplasma, observed in the side-view direction during plasma discharge operation with $f=$ (a) 11 and (b) $4 \mathrm{GHz}$ microwaves of $P_{\text {in }}=6 \mathrm{~W}$ and an Ar flow rate of $10 \mathrm{sccm}(\dot{m}=0.3 \mathrm{mg} / \mathrm{s})$. The inset is the spectrum magnified in the visible $400-460 \mathrm{~nm}$.

trace impurities in working $\mathrm{Ar}$ gas: ${ }^{102-104} \mathrm{OH}$ band $\left(\mathrm{A}^{2} \Sigma^{+}\right.$, $\left.v^{\prime}=0 \rightarrow \mathrm{X}^{2} \Pi, v^{\prime \prime}=0\right)$ at $306.4-308.9 \mathrm{~nm}, \mathrm{~N}_{2}$ 2nd positive $(0,0)$ band $\left(C^{3} \Pi_{u}, v^{\prime}=0 \rightarrow B^{3} \Pi_{g}, v^{\prime \prime}=0\right)$ at $337.1 \mathrm{~nm}, \mathrm{H}$ Balmer- $\beta\left(\mathrm{H}_{\beta}\right)$ line at $486.1 \mathrm{~nm}$, and $\mathrm{H}$ Balmer- $\alpha\left(\mathrm{H}_{\alpha}\right)$ line at $656.2 \mathrm{~nm}$. The $\mathrm{Ar}$ I line intensities in the visible region were observed to increase with decreasing flow rate (thus, decreasing pressure $p_{0}$ in the microplasma source), while those in the near-ir were to remain relatively unchanged. Moreover, visible $\mathrm{Ar}$ I lines were significantly more intense for $f=11 \mathrm{GHz}$ than for $f=4 \mathrm{GHz}$ (as partly shown in Fig. 10). These observations suggest higher plasma electron temperatures at lower flow rates and for higher microwave frequencies (as shown in Figs. 11 and 12), taking into account the upper-level excitation energies $E_{u}$ that are higher for visible Ar I lines $\left(3 p^{5} 4 s-3 p^{5} 5 p\right.$ transitions with $E_{u}=14.5-14.7 \mathrm{eV}$ from the Ar I ground state $\left.3 p^{6}{ }^{1} \mathrm{~S}_{0}\right)$ than for near-ir ones $\left(3 p^{5} 4 s-3 p^{5} 4 p\right.$ transitions with $\left.\mathrm{E}_{u}=13.0-13.3 \mathrm{eV}\right) .^{102}$

The analysis of optical emissions from the plasma has been detailed previously. ${ }^{56,57}$ The plasma electron density was measured by adding a small amount $(<1 \%)$ of $\mathrm{H}_{2}$ and analyzing the Stark broadening of the $\mathrm{H}_{\beta}$ line at $486.1 \mathrm{~nm}$. ${ }^{105,106}$ The accuracy of the electron density determined from the Stark broadening relies on the spectral resolution of the measurement system and also on the assumption of analysis of the spectral line broadening; the present accuracy was estimated to be about $\pm 20 \%$, primarily owing to the resolution $\Delta \lambda_{\text {instrum }} \approx 0.025 \mathrm{~nm}$ of the $50-\mathrm{cm}$ spectrometer system employed. Moreover, the gas/rotational temperature was measured by adding a small amount $(<1 \%)$ of $\mathrm{N}_{2}$ and analyzing the vibronic spectrum of the $\mathrm{N}_{2}$ 2nd positive $(0,2)$ band at $380.4 \mathrm{~nm}$.

Figures 11 and 12 show the plasma electron density $n_{e}$ and gas/rotational temperature $\mathrm{T}_{g} \approx \mathrm{T}_{\text {rot }}$ in the microplasma source, measured as a function of the Ar flow rate in the range $10-70 \mathrm{sccm}(\dot{m}=0.3-2.1 \mathrm{mg} / \mathrm{s})$ for $f=11$ and $4 \mathrm{GHz}$ microwaves of different $P_{\text {in }}=3-6 \mathrm{~W}$, respectively, where increasing the flow rate leads to an increase in pressure $p_{0}$ or gas density $n_{g}$ in the microplasma source (as mentioned in Sec. III A). In both $f=11$ and $4 \mathrm{GHz}$ discharges, the plasma density $n_{e}$ and the temperature $T_{\text {rot }}$ increase with increasing $\mathrm{P}_{\text {in }}$; on the other hand, $n_{e}$ increases with increasing flow rate, while $\mathrm{T}_{\text {rot }}$ slightly decreases with increasing it. The plasma density and gas temperature are in the range $n_{e} \approx(4-12) \times 10^{19}$ $\mathrm{m}^{-3}$ and $\mathrm{T}_{g} \approx \mathrm{T}_{\text {rot }} \approx 800-1000 \mathrm{~K}$, respectively, in $f=11 \mathrm{GHz}$ discharges of Fig. 11, which are $\sim 10 \%-50 \%$ higher than those $\left[n_{e} \approx(4-8) \times 10^{19} \mathrm{~m}^{-3}, \mathrm{~T}_{g} \approx \mathrm{T}_{\text {rot }} \approx 650-850 \mathrm{~K}\right]$ in $f=4 \mathrm{GHz}$ ones of Fig. 12. These $n_{e}$ values spectroscopically measured were consistent with the Langmuir probe measurements in the supersonic plasma free jet downstream of the nozzle.

Also shown in Figs. 11 and 12 are the curves of $n_{e}$ and $\mathrm{T}_{g}=$ $\mathrm{T}_{h}$ numerically simulated as in Figs. 2, 4, and 5 (with Ar only), along with those of the plasma electron temperature $\mathrm{T}_{e}$, where the numerical data on $n_{e}, \mathrm{~T}_{h}$, and $\mathrm{T}_{e}$ are line-averaged in the radial direction between the end of the antenna envelope and the inlet of the nozzle. A comparison indicates that
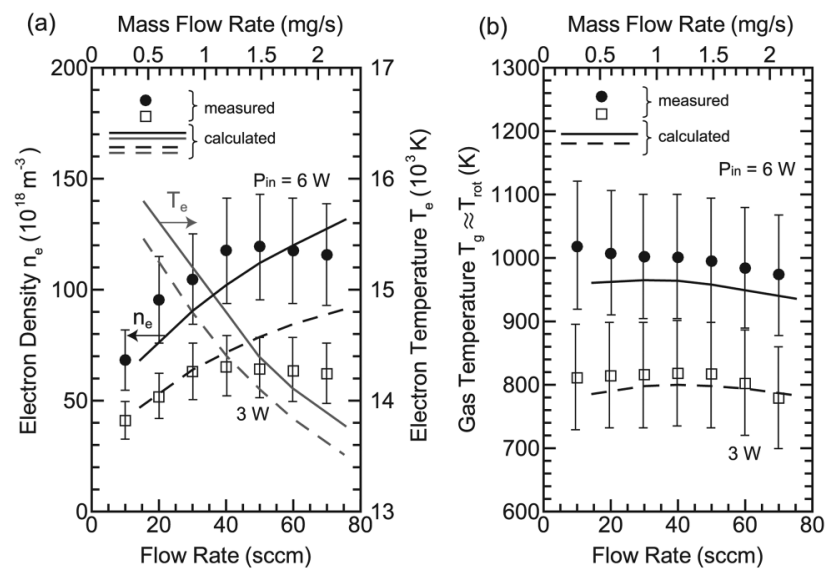

FIG. 11. (a) Plasma electron density $n_{e}$ and (b) gas/rotational temperature $T_{g} \approx T_{\text {rot }}$ in the microplasma source, measured as a function of the Ar flow rate in the range $10-70 \mathrm{sccm}(\dot{m}=0.3-2.1 \mathrm{mg} / \mathrm{s})$ with $f=11 \mathrm{GHz}$ microwaves of different $P_{\text {in }}=3-6 \mathrm{~W}$. Also shown are the curves of $T_{g}=T_{h}, n_{e}$, and electron temperature $T_{e}$ numerically simulated. 

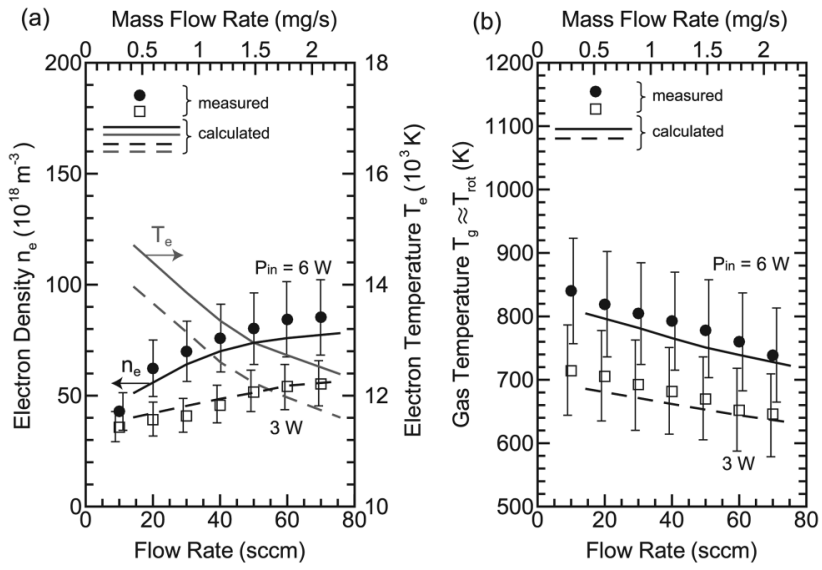

FIG. 12. (a) Plasma electron density $n_{e}$ and (b) gas/rotational temperature $T_{g} \approx T_{\text {rot }}$ in the microplasma source, measured as a function of the Ar flow rate in the range $10-70 \mathrm{sccm}$ with $f=4 \mathrm{GHz}$ microwaves of different $P_{\text {in }}=3-6 \mathrm{~W}$. Also shown are the curves of $T_{g}=T_{h}, n_{e}$, and electron temperature $T_{e}$ numerically simulated.

the experiments are in agreement with simulations, where the measured $n_{e}$ and $\mathrm{T}_{g} \approx \mathrm{T}_{\text {rot }}$ values tend to be slightly higher than those of the $n_{e}$ and $\mathrm{T}_{g}=\mathrm{T}_{h}$ simulated. In addition, the electron temperature $T_{e}$ simulated is higher for higher $f$ and $P_{\text {in }}$ of microwaves and for a lower flow rate (or, lower $p_{0}$ ), being consistent with the behavior of the optical emission spectra as mentioned with respect to Fig. 10.

It is noted that the effects of adding molecular $\mathrm{H}_{2}$ and $\mathrm{N}_{2}$ gases to monoatomic rare gas Ar plasmas have so far been studied both experimentally and numerically/theoretically (see the Appendix). ${ }^{107-119}$ In the present experiments, we did not measure the $\mathrm{T}_{e}$ as well as electron energy distribution function (EEDF), and so we cannot say quantitatively the effects of adding a small amount $(<1 \%)$ of $\mathrm{H}_{2}$ and $\mathrm{N}_{2}$ to $\mathrm{Ar}$ on the plasma properties. However, the present optical emission spectroscopy indicated that the addition of $<1 \% \mathrm{H}_{2}$ and $\mathrm{N}_{2}$ to Ar plasmas gave rise to no significant change of the $\mathrm{Ar}$ I line intensities in the visible and near-ir region (and thus no significant change of the intensity ratio of the visible Ar I lines to the near-ir ones); this implies that no significant change in the EEDF and/or $\mathrm{T}_{e}$ occurred with the $\mathrm{H}_{2}$ and $\mathrm{N}_{2}$ addition, since the upper-level excitation energies for visible Ar I lines are $>1 \mathrm{eV}$ higher than those of near-ir ones (as mentioned above). Moreover, $n_{e}$ and $\mathrm{T}_{g} \approx \mathrm{T}_{\text {rot }}$ experimentally measured with adding small amounts of $\mathrm{H}_{2}$ and $\mathrm{N}_{2}$ were found to correspond to the numerical $n_{e}$ and $\mathrm{T}_{g}=\mathrm{T}_{h}$ of pure Ar plasmas (as seen in Figs. 11 and 12), giving confidence that any changes to the plasma properties (such as $n_{e}$ and $\mathrm{T}_{g}$ ) are minimal.

The slight difference between the measured $n_{e}$ and $\mathrm{T}_{g} \approx$ $\mathrm{T}_{\text {rot }}$ and the numerical $n_{e}$ and $\mathrm{T}_{g}=\mathrm{T}_{h}$ (Figs. 11 and 12) is assumed to be due not to additives/impurities, but to a set of atomic processes, rate coefficients, energy transfer rates, and radiative energy loss rate used in simulations (Sec. II A). In effect, the additives/impurities cannot explain the difference concerned, because molecular additives/impurities such as $\mathrm{H}_{2}$ and $\mathrm{N}_{2}$ would not lead to an increase in both $n_{e}$ and $\mathrm{T}_{g}$ (Appendix).

\section{Thrust performance}

The setup for thrust measurement has also been detailed previously, ${ }^{53,56,57}$ consisting of a pendulum-type stand for cold-gas operation and a target-type stand for both cold-gas and plasma-discharge operations. The accuracy of the present thrust measurement was estimated to be about $\pm 10 \%$, relying primarily on mechanical issues of the measurement system such as the effects of friction of the knife edge on the rotational axis and those of the reflected jet plume particles on the target.

Figures 13 and 14 show the thrust performance $\left(\mathrm{F}_{\mathrm{t}}, \mathrm{I}_{\mathrm{sp}}, \eta_{\mathrm{t}}\right)$ measured as a function of the Ar flow rate for $f=11$ and $4 \mathrm{GHz}$ microwaves of different $P_{\text {in }}=0-6 \mathrm{~W}$ under plasma discharge conditions of the preceding Figs. 11 and 12, respectively. Here, the specific impulse $I_{s p}$ and thrust efficiency $\eta_{t}$ were derived from the measured thrust $F_{t}$ using Eqs. (2) and (3), and $P_{\text {in }}=0 \mathrm{~W}$ corresponds to the cold-gas operation without plasma discharge. In both $f=11$ and $4 \mathrm{GHz}$ discharges, the thrust $F_{t}$ and the specific impulse $I_{s p}$ are increased with the discharge on and with increasing $P_{i n}$; on the other hand, $F_{t}$ is increased with the increasing flow rate, while $I_{s p}$ is relatively insensitive to it. The thrust, specific impulse, and thrust efficiency are in the range $\mathrm{F}_{\mathrm{t}} \approx 0.2-1.8 \mathrm{mN}, \mathrm{I}_{\mathrm{sp}} \approx 65-90 \mathrm{~s}$, and $\eta_{\mathrm{t}} \approx 2 \%-14 \%$ in $f=11 \mathrm{GHz}$ discharges of Fig. 13, which are $\sim 10 \%-15 \%$ higher than those $\left(\mathrm{F}_{\mathrm{t}} \approx 0.2-1.6 \mathrm{mN}, \mathrm{I}_{\mathrm{sp}} \approx 60-80 \mathrm{~s}\right.$, $\left.\eta_{t} \approx 2 \%-12 \%\right)$ in $f=4 \mathrm{GHz}$ ones of Fig. 14 . The thrust efficiency $\eta_{t}$ is higher for higher $f$ and flow rate, while it tends to be higher at lower $P_{\text {in }}$; in practice, $\eta_{t}$ derived using Eq. (3) (which is often employed for the plasma thruster of electrothermal type) inherently implies that when the input power is reduced for a given flow rate $\left(\mathrm{P}_{\text {in }} \rightarrow 0 \mathrm{~W}\right.$ for a given $\left.\dot{m}\right)$, the thrust approaches to that in cold gas operation $\left(F_{t} \rightarrow F_{t 0}\right)$, and correspondingly the trust efficiency tends to be increased $\left(\eta_{t} \rightarrow 100 \%\right)$; in other words, the thrust efficiency can be traded for higher thrust and specific impulse when increasing the input power at a given propellant flow rate.

Also shown in Figs. 13 and 14 are the curves of $F_{t}, I_{s p}$, and $\eta_{t}$ calculated based on numerical simulations of the nozzle flow as in Fig. 7, where the gas or the heavy particle temperature $\mathrm{T}_{g}=\mathrm{T}_{h}$ in the microplasma source was assumed to be the room temperature in cold gas operation. A comparison indicates that the experiments are in agreement with simulations, where the measured $\mathrm{F}_{t}, \mathrm{I}_{\mathrm{sp}}$, and $\eta_{t}$ values tend to be slightly higher than those obtained from numerical simulations. The slight difference in thrust performance between experiments and simulations is ascribed primarily to that in gas temperature $\mathrm{T}_{g}$ in the plasma source, which in turn is assumed to be due to atomic processes and rate constants used in simulations (as mentioned in Sec. III B with respect to Figs. 11 and 12). In effect, the thrust consisting of the momentum and pressure 
(a) Mass Flow Rate $(\mathrm{mg} / \mathrm{s})$

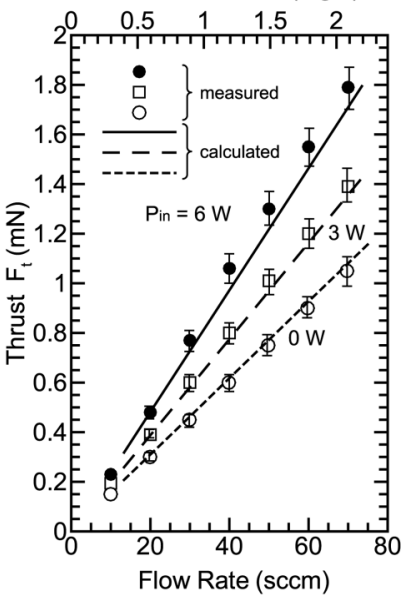

(b) Mass Flow Rate (mg/s)

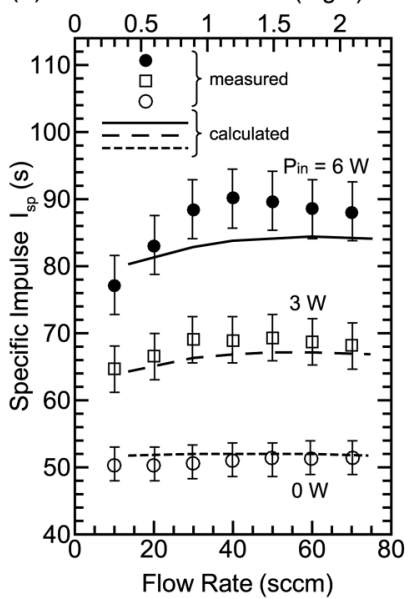

(c) Mass Flow Rate ( $\mathrm{mg} / \mathrm{s})$

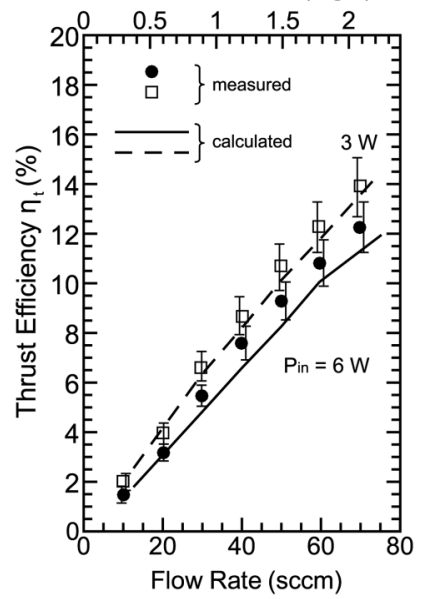

FIG. 13. Thrust performance [(a) $F_{t}$ (b) $I_{\mathrm{sp}}$, (c) $\eta_{\mathrm{t}}$ measured as a function of the Ar flow rate with $f=11 \mathrm{GHz}$ microwaves of different $P_{\text {in }}=0-6 \mathrm{~W}$ under plasma discharge conditions of Fig. 11 , where $P_{\text {in }}=0 \mathrm{~W}$ corresponds to the cold-gas operation. Also shown are the curves of $F_{t}, I_{\mathrm{sp}}$, and $\eta_{t}$ numerically simulated.

thrust [as Eq. (1)] is given by

$$
\mathrm{F}_{\mathrm{t}}=\dot{m} u_{\mathrm{ex}}+\left(p_{\mathrm{ex}}-p_{b}\right) \mathrm{A}_{\mathrm{ex}}
$$

in one dimension, ${ }^{100}$ where $u_{\mathrm{ex}}$ and $p_{\mathrm{ex}}$ denote the exhaust flow velocity and pressure at the nozzle exit, respectively, $p_{b}$ the background or ambient pressure outside the exit, and $A_{\text {ex }}$ the cross-sectional area of the nozzle exit; then, for simplicity, further assuming the isentropic nozzle flow of perfect gases and its infinite $\left[p_{\mathrm{ex}} \ll p_{0}\right.$ in Eq. (5)] and ideal/ optimum $\left(p_{\mathrm{ex}} \approx p_{b}\right)$ expansion conditions, ${ }^{99,100}$ Eq. (5) becomes $u_{\mathrm{ex}} \approx u_{\infty}=\sqrt{2 \gamma \mathrm{RT}_{0} /(\gamma-1)}$, and Eq. (6) becomes $\mathrm{F}_{\mathrm{t}} \approx \dot{m} u_{\infty}=\dot{m} \sqrt{2 \gamma \mathrm{RT}_{0} /(\gamma-1)}$; under these conditions, the thrust performance is assumed to be increased with increasing source or stagnation temperature $\mathrm{T}_{0}\left(=\mathrm{T}_{g}\right)$ for a given input power $P_{\text {in }}$ and propellant flow rate $\dot{m}\left[F_{t} \propto \sqrt{T_{0}}\right.$, $\left.I_{\text {sp }}=F_{t} /(\dot{m} g) \propto \sqrt{T_{0}}, \eta_{t}=F_{t}^{2} /\left(2 \dot{m} P_{\text {in }}+F_{t 0}^{2}\right) \propto T_{0}\right]$.

Thus, the superiority of higher frequency $f=11 \mathrm{GHz}$ microwaves with the length $L_{\mathrm{s}}=4.5 \mathrm{~cm}\left[\approx \lambda / 4\left(\approx \lambda_{\mathrm{sw}} / 4\right)\right]$ of the plasma source chamber was demonstrated experimentally for the microplasma thruster, in terms of efficient microplasma generation (higher $n_{e}$ ), gas heating (higher $\mathrm{T}_{g}$ ), and thrust
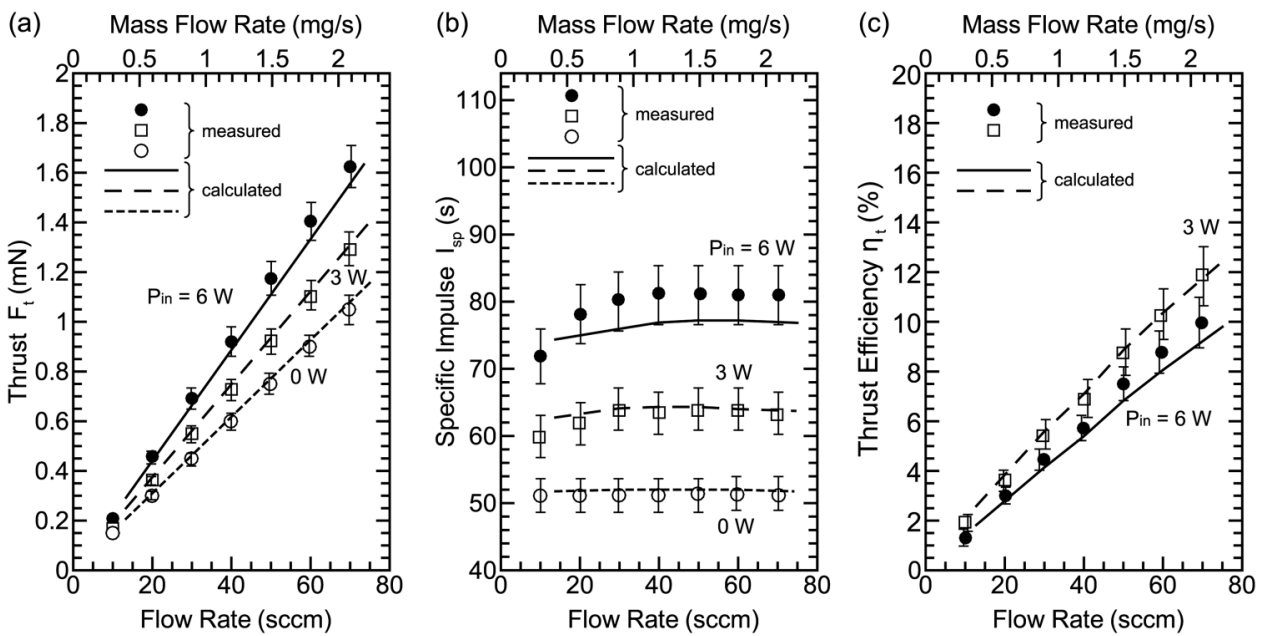

FIG. 14. Thrust performance $\left[\left(\right.\right.$ a) $F_{t}$, (b) $I_{\mathrm{sp}}$, (c) $\left.\eta_{t}\right]$ measured as a function of the Ar flow rate with $f=4 \mathrm{GHz}$ microwaves of different $P_{\text {in }}=0-6 \mathrm{~W}$ under plasma discharge conditions of Fig. 12 . Also shown are the curves of $F_{t}, I_{\mathrm{sp}}$, and $\eta_{t}$ numerically simulated. 
TABLE II. Comparison of representative operating parameters/conditions and thrust performance for several microplasma thrusters of electrothermal type (with power inputs on the order of $1-10 \mathrm{~W}$ ) that have been reported in the literature. ${ }^{33-49}$

\begin{tabular}{|c|c|c|c|c|c|c|c|c|c|}
\hline \multirow[b]{2}{*}{ Category } & \multirow[b]{2}{*}{ Property } & \multicolumn{8}{|c|}{ Microplasma thruster of electrothermal type } \\
\hline & & \multicolumn{2}{|c|}{ SWP $^{a}$} & Arc jet & HCT $^{\mathrm{b}}$ & $\mathrm{MPT}^{\mathrm{C}}$ & $M C D^{d}$ & $\mathbf{P R}^{\mathrm{e}}$ & SSRR $^{\prime}$ \\
\hline \multirow[t]{2}{*}{ Plasma source } & $f(\mathrm{GHz})$ & 11 & 4 & dc & dc & dc & 0.020 & 0.01378 & 2.42 \\
\hline & $P_{\text {in }}(\mathrm{W})$ & 6 & 6 & 3.6 & 13 & 0.65 & 0.084 & 32 & 1.1 \\
\hline \multirow[t]{3}{*}{ Propellant } & Gas & $\mathrm{Ar}$ & $\mathrm{Ar}$ & $\mathrm{N}_{2}$ & $\mathrm{Ar}$ & $\mathrm{Ar}$ & $\mathrm{Ar}$ & $\mathrm{Xe}$ & $\mathrm{Xe}$ \\
\hline & $\dot{m}(\mathrm{mg} / \mathrm{s})$ & 2.1 & 2.1 & 1.0 & 1.0 & 0.15 & 0.44 & 5.16 & 4.0 \\
\hline & $p_{0}(\mathrm{kPa})$ & 40 & 38 & 80 & - & $\sim 10$ & $\sim 40$ & 1.0 & 65 \\
\hline \multirow[t]{2}{*}{ Plasma condition } & $n_{e}\left(10^{20} \mathrm{~m}^{-3}\right)$ & 1.2 & 0.85 & - & - & $\sim 1$ & $\sim 0.8$ & $\sim 0.01$ & - \\
\hline & $T_{g}(\mathrm{~K})$ & 970 & 740 & $\sim 1500$ & - & $\sim 1000$ & $\sim 500$ & $\sim 1000$ & - \\
\hline \multirow[t]{4}{*}{ Thrust performance } & $F_{t}(\mathrm{mN})$ & 1.8 & 1.6 & 1.4 & $\sim 1.9$ & 0.1 & 0.278 & 1.4 & 2.15 \\
\hline & $l_{\mathrm{sp}}(\mathrm{s})$ & 88 & 81 & 138 & 167 & 74 & 65 & 28 & 55 \\
\hline & $\eta_{t}(\%)^{g}$ & 12 & 9.7 & 24 & 14 & $5.0^{h}$ & $59^{h}$ & $0.59^{h}$ & $37^{h}$ \\
\hline & $F_{t 0}(\mathrm{mN})$ & 1.05 & 1.05 & $\sim 0.4$ & $\sim 0.7$ & 0.067 & $0.24^{\mathrm{h}}$ & 0.87 & $1.75^{\mathrm{h}}$ \\
\hline Ref. $(E / N)^{i}$ & & \multicolumn{2}{|c|}{ Present study (E) } & $34(\mathrm{E})$ & $35(E)$ & $37(\mathrm{~N})$ & $39(\mathrm{~N})$ & $45,46(E)$ & $49(\mathrm{E})$ \\
\hline
\end{tabular}

a Surface wave-excited plasma.

${ }^{\mathrm{b}}$ Hollow cathode thruster.

'Microplasma thruster (consisting of a dc microdischarge).

${ }^{\mathrm{d} M i c r o c a v i t y}$ discharge.

${ }^{e}$ Pocket rocket (consisting of a capacitively coupled if discharge).

fSplitline split-ring resonator.

${ }^{9}$ Calculated using Eq. (3).

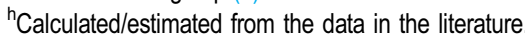

' $(E / N)$ indicates an experimental/numerical study.

performance (higher $F_{t}, I_{s p}, \eta_{t}$ ), as expected from the numerical analysis in Sec. II. A comparison of representative operating parameters/conditions and thrust performance is given in Table II, for several microplasma thrusters of electrothermal type (with power inputs on the order of 1-10 W) that have so far been reported in the literature. ${ }^{33-49}$

\section{CONCLUSIONS}

We have developed numerically and experimentally the microwave-driven microplasma thruster of electrothermal type with X-band $(f=11 \mathrm{GHz})$ microwaves and Ar as a propellant. The emphasis was placed on a better understanding of the distinguished features of microplasma generation by X-band microwaves, compared with those by S-band $(f=4.0 \mathrm{GHz})$ microwaves, and the following micronozzle flow and thrust performance. The thruster consisted of a microplasma source followed by a converging-diverging micronozzle; the former was made of a dielectric chamber $2 \mathrm{~mm}$ in the inner diameter and $L_{s}=3-12 \mathrm{~mm}$ long covered with a metal shroud grounded, having a metal rod antenna on the axis covered with a dielectric envelope $1.2 \mathrm{~mm}$ in the outer diameter; and the latter was $1 \mathrm{~mm}$ long with a throat $0.2 \mathrm{~mm}$ in diameter. Azimuthally symmetric SWPs were established in the annular space between dielectrics of the plasma chamber and antenna envelope by microwaves at input powers of $P_{\text {in }} \leq 6 \mathrm{~W}$, with the source pressure being in the range $2-50 \mathrm{kPa}$ at mass flow rates of $\dot{m}=0.3-2.1 \mathrm{mg} / \mathrm{s}$ (flow rates of $10-70 \mathrm{sccm}$ ).
The microplasma generation, micronozzle flow, and thrust performance were numerically analyzed by using a twodimensional fluid model, coupled with an electromagnetic model for microwaves interacting with plasmas in the source region. Simulations were made for $f=11$ and $4 \mathrm{GHz}$ microwaves with different lengths $L_{s}$ of the plasma source chamber, indicating that higher frequency $f=11 \mathrm{GHz}$ with $\mathrm{L}_{\mathrm{s}}=4.5 \mathrm{~mm}(\approx \lambda / 4)$ is preferred for the microplasma thruster, in terms of efficient microwave absorption (higher $\mathrm{Q}_{\mathrm{abs}} / \overline{\mathrm{Q}}_{\mathrm{abs}}$ ), plasma generation (higher $n_{e}$ ), gas heating (higher $\mathrm{T}_{h}$ ), and thus thrust performance (higher $\mathrm{F}_{t}, \mathrm{I}_{\mathrm{sp}}, \eta_{\mathrm{t}}$ ), as well as system compactness (shorter $L_{s}$ ). Here, $\lambda=\lambda_{0} / \sqrt{\varepsilon_{d}}$ is the wavelength of the driving microwaves propagating in the dielectric $(\lambda=13.97$ and $38.44 \mathrm{~mm}$ for $f=11$ and $4 \mathrm{GHz}$, respectively, with $\varepsilon_{d}=3.8$ ), and $\lambda_{0}$ is the wavelength in free space.

Moreover, $f=11 \mathrm{GHz}$ microwaves with longer $\mathrm{L}_{\mathrm{s}}=10.5 \mathrm{~mm}$ $(\approx 3 \lambda / 4)$ exhibited the formation of standing-wave striationlike (or periodic) plasma structures in the axial direction: the plasma electron density $n_{e}$ and the temperature $\mathrm{T}_{e}$, along with the heavy particle temperature $T_{h}$, exhibited their two local maxima at axial positions separated by $\Delta z \sim 6 \mathrm{~mm}$; this corresponded to two local peaks of the microwave field strength $\left|E_{z}\right|$ and absorbed power density $Q_{\text {abs }}$ at axial positions separated also by $\Delta z \sim 6-7 \mathrm{~mm}$ at both the outer and inner plasma-dielectric interfaces (four local peaks of $\left|E_{z}\right|$ and $\mathrm{Q}_{\mathrm{abs}}$ in total). Similar structures have been observed in experiments of linear SWPs $(f=2.45 \mathrm{GHz})$ of conventional scale, which showed local periodic peaks of the electron density ${ }^{88}$ and the optical emission intensity ${ }^{89,90}$ along the axis. These 
two local maxima/peaks separated by $\Delta z \approx 6-7 \mathrm{~mm}$ indicate the antinodes of standing electromagnetic waves or surface waves that occur on both sides of the node, giving the half-wavelength $\lambda_{\mathrm{sw}} / 2 \approx 6-7 \mathrm{~mm}$ and thus the wavelength $\lambda_{\mathrm{sw}} \approx 12-14 \mathrm{~mm}$ of the waves; thus, it follows that the wavelength $\lambda_{\mathrm{sw}}$ of standing surface waves excited under the present conditions is in agreement with the driving microwave wavelength $\lambda$. Hence, we can totally consider that for a given $P_{\text {in }}$ and $\dot{m}$, higher $f$ microwaves with $L_{s} \approx \lambda / 4\left(\approx \lambda_{\mathrm{sw}} / 4\right)$, which correspond to the quarter-wavelength resonance (or the lowest resonance mode of standing surface waves), are preferred for higher thrust performance and system compactness, resulting from more efficient microwave absorption, plasma generation, and gas heating; in practice, the surfacewave resonance density $n_{\mathrm{cr}}=n_{c}\left(1+\varepsilon_{d}\right)$ is expected to be increased with increasing $f=\omega / 2 \pi$, when surface waves are excited and propagate along plasma-dielectric interfaces in overdense plasmas $\left(n_{e}>n_{c}\right) ;{ }^{59-64}$ and the gas or heavy particle temperature $\mathrm{T}_{g}=\mathrm{T}_{h}$ should be a direct or the most sensitive measure for the thrust performance.

Experiments were made with $f=11$ and $4 \mathrm{GHz}$ microwaves with the respective $L_{s}=4.5$ and $10.5 \mathrm{~mm}(\approx \lambda / 4)$, where the plasma electron density and gas temperature were measured in the microplasma source at around the end of the dielectric antenna envelope or just upstream of the nozzle inlet, by optical emission spectroscopy with a small amount of $\mathrm{H}_{2}$ and $\mathrm{N}_{2}$ added. The electron density and gas temperature measured for $f=11 \mathrm{GHz}$ were in the range $n_{e} \approx(4-12) \times 10^{19} \mathrm{~m}^{-3}$ and $\mathrm{T}_{g} \approx \mathrm{T}_{\text {rot }} \approx 800-1000 \mathrm{~K}$, which were $\sim 10 \%-50 \%$ higher than those for $f=4 \mathrm{GHz}$. The thrust performance was also measured by using a target-type microthrust stand, giving a thrust in the range $\mathrm{F}_{\mathrm{t}} \approx 0.2-1.8 \mathrm{mN}$, a specific impulse in the range $I_{\mathrm{sp}} \approx 65-90 \mathrm{~s}$, and a thrust efficiency in the range $\eta_{t} \approx 2-14 \%$ for $f=11 \mathrm{GHz}$, which were $\sim 10 \%-15 \%$ higher than those for $f=4 \mathrm{GHz}$. These experimental results were consistent with those expected from numerical simulations, depending on microwave frequency, power, chamber size, and gas flow rate. Hence, both numerically and experimentally, we can conclude the superiority of higher $f$ microwaves with $L_{\mathrm{s}} \approx \lambda / 4\left(\approx \lambda_{\mathrm{sw}} / 4\right)$ for the microplasma thruster, in terms of efficient plasma generation, gas heating, and thus thrust performance, as well as system compactness.

\section{ACKNOWLEDGMENTS}

This work was supported in part by a Grant-in-Aid for Scientific Research (No. 18030007) from the Japan Society for the Promotion of Science. One of the authors (K.O.) gratefully thanks Professor Y. Setsuhara (Osaka University) for kind support throughout preparing this article.

\section{APPENDIX: EFFECTS OF $\mathrm{H}_{2}$ AND $\mathrm{N}_{2}$ ADDITION TO AR PLASMAS}

The effects of adding molecular $\mathrm{H}_{2}$ (Refs. 107-111) and $\mathrm{N}_{2}$ (Refs. 112-119) gases to monoatomic rare gas Ar plasmas have so far been studied both experimentally and numerically/theoretically at low pressures ( 0.1-10 Pa). Briefly, compared with rare gas atoms, such molecules are characterized by various low energy rotational, vibrational, and electronic energy states that are excited by plasma electrons; then, the excited states of molecules are quenched by collisions with background gas atoms/molecules, thus providing a pathway for transfer of the electron energy to gases through a series of inelastic collision processes. ${ }^{39}$ When $\mathrm{N}_{2}$ is added to Ar, a cooling effect occurs on the plasma electrons, and the electron temperature $\mathrm{T}_{e}$ tends to be reduced. ${ }^{117-119}$ The EEDFs in pure Ar plasmas are nearly Maxwellian below the inelastic collision thresholds with a slight depletion of electrons for energies $E_{e}>11.6 \mathrm{eV}$ [the first excitation threshold for Ar or the excitation energy for $\left.\operatorname{Ar}{ }^{*}\left(3 p^{5} 4 s^{3} \mathrm{P}_{2}\right)\right]{ }^{116}$ with increasing the fraction of $\mathrm{N}_{2}$, a reduction in the EEDF occurs in the range $E_{e} \sim 1-5 \mathrm{eV}$, owing to some resonant electron-molecule vibrational excitation processes. ${ }^{112,116-118}$ In these situations, the electron density $n_{e}$ tends to decrease $\mathrm{e}^{116,118}$ and the gas temperature $\mathrm{T}_{g}$ tends to increase ${ }^{113}$ with the $\mathrm{N}_{2}$ fraction. Moreover, the addition of $\mathrm{N}_{2}$ may alter the plasma properties through a resonant electronic energy transfer between $\mathrm{Ar}$ metastable atoms and $\mathrm{N}_{2}$ molecules $\left[\mathrm{Ar} *\left(3 p^{5} 4 s^{3} \mathrm{P}_{0,2}\right)+\mathrm{N}_{2}\left(\mathrm{X}^{1} \Sigma_{g}^{+}\right) \rightarrow \operatorname{Ar}\left(3 p^{6}{ }^{1} \mathrm{~S}_{0}\right)+\mathrm{N}_{2}\left(\mathrm{C}^{3} \Pi_{u}\right)\right],{ }^{120,121}$ which can lead to an overestimation of the gas temperature derived from the vibronic spectrum of the $\mathrm{N}_{2}$ 2nd positive band assuming $\mathrm{T}_{g} \approx \mathrm{T}_{\text {rot. }}{ }^{115}$

On the other hand, when $\mathrm{H}_{2}$ is added to Ar, a little different behavior occurs owing to a relatively large difference in magnitude of the ionization cross section by electron impact between $\mathrm{Ar}$ and $\mathrm{H}_{2}$ [e.g., the total ionization cross section at $\mathrm{E}_{e}=50 \mathrm{eV}$ is $\sigma_{\mathrm{T}} /\left(\pi a_{0}^{2}\right) \approx 2.88$ for $\mathrm{Ar}, 2.20$ for $\mathrm{N}_{2}$, and $1.07 \mathrm{H}_{2}{ }^{122}$ where $a_{0}$ denotes the Bohr radius], and to a relatively large difference in mass of ion and neutral atoms/molecules between $\mathrm{Ar}$ and $\mathrm{H}_{2}$ (e.g., the mass in amu or $\mathrm{g} / \mathrm{mol}$ is $M \approx 39.94$ for $\mathrm{Ar}, 28.01$ for $\mathrm{N}_{2}$, and 2.015 for $\mathrm{H}_{2}$ ). In these situations, with increasing the fraction of $\mathrm{H}_{2}$, the electron density $n_{e}$ tends to decrease, ${ }^{107-111}$ the electron temperature $\mathrm{T}_{e}$ tends to increase, ${ }^{108-111}$ while the gas temperature $\mathrm{T}_{g}$ does not vary significantly. ${ }^{110}$ The EEDFs exhibit two distinct regions separated by a kink at electron energy which increases with the $\mathrm{H}_{2}$ fraction from $\mathrm{E}_{e} \approx 12 \mathrm{eV}$ in pure Ar plasmas to $\mathrm{E}_{e} \approx 22 \mathrm{eV}$ in pure $\mathrm{H}_{2}$ plasmas; ${ }^{108,110}$ the EEDFs with two distinct regions of two different slopes can be approximated by a bi-Maxwellian distribution with two distinct electron temperatures, where the slope of the low-energy part decreases with increasing the $\mathrm{H}_{2}$ fraction, corresponding to the increase of $\mathrm{T}_{e}$.

\section{REFERENCES}

${ }^{1}$ H. Helvajian and S. W. Janson, in Microengineering Aerospace Systems, edited by H. Helvajian (AIAA, Reston, VA, 1999), Chap. II, pp. 29-72.

${ }^{2}$ Small Satellites: Past, Present, and Future, edited by $\mathrm{H}$. Helvajian and S. W. Janson (AIAA, Reston, VA, 2009).

${ }^{3}$ M. Peck, IEEE Spectrum, Vol. 48, August, 2011, p. 42.

${ }^{4}$ Micropropulsion for Small Spacecraft, edited by M. M. Micci and A. D. Ketsdever (AIAA, Reston, VA, 2000).

${ }^{\mathbf{5}} \mathrm{M}$. Tajmar, Advanced Space Propulsion Systems (Springer, Vienna, 2003), Chap. 6, pp. 99-105.

${ }^{6} \mathrm{~J}$. Schein, in MEMS and Microstructures in Aerospace Applications, edited by R. Osiander, M. A. G. Darrin, and J. L. Champion (CRC, Boca Raton, FL, 2006), Chap. 11, pp. 229-267. 
${ }^{7} \mathrm{~K}$. G. Xu, in 33rd International Electric Propulsion Conference, IEPC2013-084, Washington DC, 2013.

${ }^{8}$ M. Keidar, T. Zhuang, A. Shashurin, G. Teel, D. Chiu, J. Lukas, S. Haque, and L. Brieda, Plasma Phys. Control. Fusion 57, 014005 (2015).

${ }^{9}$ D. Werner, Aerospace America, July/August, 2017, p. 32.

${ }^{10}$ A. R. Tummala and A. Dutta, Aerospace 4, 58 (2017).

"I. Levchenko, K. Bazaka, Y. Ding, Y. Raitses, S. Mazouffre, T. Henning, P. J. Klar, S. Shinohara, J. Schein, L. Garrigues, M. Kim, D. Lev, F. Taccogna, R. W. Boswell, C. Charles, H. Koizumi, Y. Shen, C. Scharlemann, M. Keidar, and S. Xu, Appl. Phys. Rev. 5, 011104 (2018).

12I. Levchenko, S. Xu, G. Teel, D. Mariotti, M. L. R. Walker, and M. Keidar, Nat. Commun. 9, 879 (2018).

${ }^{13}$ D. Krejci and P. Lozano, Proc. IEEE 106, 362 (2018)

${ }^{14} \mathrm{D}$. M. Goebel and I. Katz, Fundamentals of Electric Propulsion: Ion and Hall Thrusters (Wiley, New York, 2008).

${ }^{15} \mathrm{H}$. Koizumi and H. Kuninaka, J. Propul. Power 26, 601 (2010).

${ }^{16} \mathrm{~J}$. Browning, C. Lee, D. Plumlee, S. Shawver, S. M. Loo, M. Yates, M. McCrink, and J. Taff, IEEE Trans Plasma Sci. 39, 3187 (2011).

${ }^{17}$ R. E. Wirz, in Joint Conference of 30th International Symposium on Space Technology and Science, 34th International Electric Propulsion Conference, and 6th Nano-satellite Symposium, IEPC-2015-275/ISTS-2015-b-275, Kobe, Japan, 2015.

18B. Dankongkakula and R. E. Wirz, J. Appl. Phys. 122, 243303 (2017).

${ }^{19} \mathrm{H}$. Koizumi, K. Komurasaki, J. Aoyama, and K. Yamaguchi, J. Propul. Power 34, 960 (2018).

${ }^{\mathbf{2 0}}$ T. Ito and M. A. Cappelli, Appl. Phys. Lett. 89, 061501 (2006).

${ }^{21}$ T. Ito, N. Gascon, W. S. Crawford, and M. A. Cappelli, J. Propul. Power 23, 1068 (2007).

${ }^{\mathbf{2 2}} \mathrm{M}$. Tajmar, A. Genovese, and W. Steiger, J. Propul. Power 20, 211 (2004).

${ }^{23}$ D. Bock and M. Tajmar, Acta Astronaut. 144, 422 (2018).

${ }^{24}$ S. Castro and R. Bocanegra, Appl. Phys. Lett. 88, 123105 (2006).

${ }^{25}$ J. A. Nabity and J. W. Daily, J. Propul. Power 34, 260 (2018).

${ }^{26}$ C. Charles, R. W. Boswell, and K. Takahashi, Appl. Phys. Lett. 102, 223510 (2013).

${ }^{27} \mathrm{~K}$. Takahashi, C. Charles, R. Boswell, and A. Ando, Plasma Sources Sci. Technol. 23, 044004 (2014).

28J. P. Sheehan, T. A. Collard, F. H. Ebersohn, and B. W. Longmier, in Joint Conference of 30th International Symposium on Space Technology and Science, 34th International Electric Propulsion Conference, and 6th Nanosatellite Symposium, EPC-2015-243/ISTS-2015-b-243, Kobe, Japan, 2015.

${ }^{29}$ T. A. Collard, M. P. Byrne, S. T. Hepner, C. J. Durot, and B. A. Jorns, in 35th International Electric Propulsion Conference, IEPC-2017-335, Atlanta, GA, 2017.

${ }^{30}$ S. N. Bathgate, M. M. M. Bilek, and D. R. Mckenzie, Plasma Sci. Technol. 19, 083001 (2017).

${ }^{31}$ J. Aoyagi, M. Mukai, Y. Kamishima, T. Sasaki, K. Shintani, H. Takegahara, T. Wakizono, and M. Sugiki, Vacuum 83, 72 (2008).

${ }^{32}$ M. Coletti, F. Guarducci, and S. B. Gabriel, Acta Astronaut. 69, 200 (2011).

${ }^{33} \mathrm{H}$. Horisawa and I. Kimura, Vacuum 59, 106 (2000).

${ }^{34} \mathrm{H}$. Horisawa, K. Onodera, T. Noda, and I. Kimura, Vacuum 80, 1244 (2006).

${ }^{35}$ A. N. Grubisic and S. B. Gabriel, J. Propul. Power 32, 810 (2016).

${ }^{36}$ P. S. Kothnur and L. L. Raja, Contrib. Plasma Phys. 47, 9 (2007).

${ }^{37}$ T. Deconinck, S. Mahadevan, and L. L. Raja, J. Appl. Phys. 106, 063305 (2009).

${ }^{38} \mathrm{M}$. de Chadenedes, D. Ahern, J. Alaimo, J. -H. Cho, S. -J. Park, J. G. Eden, R. L. Burton, J. K. Yoon, S. Garrett, H. Sitaraman, L. L. Raja, J. LaystromWoodard, G. Benavides, and D. Carroll, in 46th AIAA/ASME/SAE/ASEE Joint Propulsion Conference, AIAA-2010-6616, Nashville, TN, 2010.

${ }^{39} \mathrm{H}$. Sitaraman and L. L. Raja, J. Phys. D Appl. Phys. 45, 185201 (2012).

${ }^{40}$ A. Dunaevsky, Y. Raitses, and N. J. Fisch, Appl. Phys. Lett. 88, 251502 (2006).

${ }^{41}$ C. Charles and R. W. Boswell, Plasma Sources Sci. Technol. 21, 022002 (2012).

${ }^{42}$ A. Greig, C. Charles, R. Hawkins, and R. Boswell, Appl. Phys. Lett. 103, 074101 (2013).
${ }^{43}$ A. Greig, C. Charles, N. Paulin, and R. W. Boswell, Appl. Phys. Lett. 105 054102 (2014)

${ }^{44}$ C. Charles, A. Bish, R. W. Boswell, J. Dedrick, A. Greig, R. Hawkins, and T. S. Ho, Plasma Chem. Plasma Process 36, 29 (2016).

${ }^{45}$ C. Charles, R. W. Boswell, A. Bish, V. Khayms, and E. F. Scholz, Front. Phys. 4, 19 (2016).

${ }^{46}$ T. S. Ho, C. Charles, and R. W. Boswell, Front. Phys. 4, 55 (2017).

${ }^{47}$ T. S. Ho, C. Charles, and R. Boswell, J. Appl. Phys. 123, 173301 (2018).

${ }^{48}$ J. Yang, Y. Xu, Z. Meng, and T. Yang, Phys. Plasmas 15, 023503 (2008).

${ }^{49}$ P. Sturesson, R. Seton, L. Klintberg, G. Thornell, and A. Persson, "Effect of resistive and plasma heating on the specific impulse of a ceramic cold gas thruster," IEEE J. Microelectromech. Syst. 28(1), 1 (2019).

${ }^{50}$ Y. Takao and K. Ono, Plasma Sources Sci. Technol. 15, 211 (2006).

${ }^{51}$ Y. Takao, K. Ono, K. Takahashi, and Y. Setsuhara, Thin Solid Films 506-507, 592 (2006).

${ }^{52}$ Y. Takao, K. Ono, K. Takahashi, and K. Eriguchi, Jpn. J. Appl. Phys. Pt. 1 45, 8235 (2006).

${ }^{53}$ Y. Takao, K. Eriguchi, and K. Ono, J. Appl. Phys. 101, 123307 (2007).

${ }^{54}$ Y. Takao, T. Takahashi, K. Eriguchi, and K. Ono, Pure Appl. Chem. 80, 2013 (2008).

${ }^{55}$ T. Takahashi, Y. Takao, K. Eriguchi, and K. Ono, J. Phys. D Appl. Phys. 41, 194005 (2008)

${ }^{\mathbf{5 6}}$ T. Takahashi, Y. Takao, K. Eriguchi, and K. Ono, Phys. Plasmas 16, 083505 (2009).

${ }^{\mathbf{5 7}}$ T. Takahashi, Y. Ichida, Y. Takao, K. Eriguchi, and K. Ono, Phys. Plasmas 18, 063505 (2011).

${ }^{58}$ T. Kawanabe, T. Takahashi, Y. Takao, K. Eriguchi, and K. Ono, in 32nd International Electric Propulsion Conference, IEPC-2011-262, Wiesbaden, Germany, 2011.

${ }^{59}$ M. Moisan, A. Shivarova, and A. W. Trivelpiece, Plasma Phys. 24, 1331 (1982). ${ }^{60}$ C. M. Ferreira, J. Phys. D Appl. Phys. 16, 1673 (1983).

${ }^{61}$ M. Moisan and Z. Zakrewski, J. Phys. D Appl. Phys. 24, 1025 (1991).

62Z. Zakrewski and M. Moisan, J. Plasma Sources Sci. Technol. 4, 379 (1995).

${ }^{63}$ I. P. Ganachev and H. Sugai, J. Plasma Sources Sci. Technol. 11, A178 (2002).

${ }^{64} \mathrm{M}$. A. Lieberman and A. J. Lichtenberg, Principles of Plasma Discharges and Materials Processing, 2nd ed. (Wiley, Hoboken, NJ, 2005), Chap. 12.1, pp. 462-470; ibid. Chap. 13.3, pp. 527-532.

${ }^{65} \mathrm{M}$. Tuda and K. Ono, J. Vac. Sci. Technol. A 16, 2832 (1998).

${ }^{66}$ M. Tuda, K. Ono, H. Ootera, M. Tsuchihashi, M. Hanazaki, and T. Komemura, J. Vac. Sci. Technol. A 18, 840 (2000).

${ }^{67}$ H. Kousaka and K. Ono, Jpn. J. Appl. Phys. Pt. 141, 2199 (2002).

${ }^{68} \mathrm{H}$. Kousaka and K. Ono, Plasma Sources Sci. Technol. 12, 273 (2003).

${ }^{69} \mathrm{H}$. Kousaka, N. Umemura, K. Ono, and J. Xu, Jpn. J. Appl. Phys. Pt. 2 44, L1154 (2005).

${ }^{70}$ S. Kar, L. Alberts, and H. Kousaka, AIP Adv. 5, 017104 (2015).

${ }^{71}$ S. Kar, H. Kousaka, and L. L. Raja, J. Appl. Phys. 117, 183302 (2015).

72Z. Q. Xie and C. M. Lyneis, Rev. Sci. Instrum. 66, 4218 (1995).

${ }^{73}$ M. Schlapp, R. Trassl, E. Sazborn, R. W. McCullough, T. K. McLaughlin, and H. B. Gilbody, Nucl. Instrum. Methods B 98, 525 (1995).

${ }^{74}$ P. Grübling, J. Hollandt, and G. Ulm, Nucl. Instrum. Methods A 437, 152 (1999).

${ }^{75}$ X. Xiang, B. Kupczyk, J. Booske, and J. Scharer, J. Appl. Phys. 115, 063301 (2014).

${ }^{7_{6}}$ J. Xue and J. A. Hopwood, IEEE Trans. Plasma Sci. 37, 816 (2009).

${ }^{77} \mathrm{~J}$. Hopwood, A. R. Hoskinson, and J. Gregório, Plasma Sources Sci. Technol. 23, 064002 (2014).

${ }^{78}$ A. R. Hoskinson, J. Gregório, S. Parsons, and J. Hopwood, J. Appl. Phys. 117, 163301 (2015).

${ }^{79}$ D. Levko and L. L. Raja, J. Appl. Phys. 118, 043303 (2015).

${ }^{80} \mathrm{~J}$. Gregório, A. R. Hoskinson, and J. Hopwood, J. Appl. Phys. 118, 083305 (2015).

${ }^{81}$ A. Grainer, C. Boisse-Laporte, P. Leprince, J. Marec, and P. Nghiem, J. Phys. D Appl. Phys. 20, 204 (1987).

${ }^{82} \mathrm{M}$. Zethoff and U. Kortshagen, J. Phys. D Appl. Phys. 25, 1574 (1992).

${ }^{83}$ G. Mur, IEEE Trans. Electromagn. Compat. 23, 377 (1981). 
${ }^{84}$ Note that there is a misprint in the conservation equation for plasma electrons in the previous paper (Ref. 56). The first term on the right-hand side of Eq. (11) therein should be replaced by $\nabla \cdot\left(\mathrm{D}_{a} \nabla n_{e}\right)$.

${ }^{85} \mathrm{~K}$. S. Yee, IEEE Trans. Antennas Propagat. 14, 302 (1966).

${ }^{86}$ S. Yoon and A. Jameson, AIAA J. 26, 1025 (1988).

${ }^{87}$ M. Nagatsu, G. Xu, M. Yamage, M. Kanoh, and H. Sugai, Jpn. J. Appl. Phys. Pt. 2 35, L341 (1996).

${ }^{88}$ K. Fujiwara, T. Okuya, M. Yanagisawa, and H. Shindo, Jpn. J. Appl. Phys. Pt. 1 42, 7536 (2003).

${ }^{89}$ V. Atanassov and E. Mateev, J. Phys. Conf. Ser. 63, 012025 (2007).

${ }^{90}$ J. J. Narendra, T. A. Grotjohn, and J. Asmussen, Plasma Sources Sci. Technol. 17, 035027 (2008).

${ }^{91}$ I. Ghanashev, M. Nagatsu, and H. Sugai, Jpn. J. Appl. Phys. Pt. 1 36, 337 (1997).

${ }^{92}$ I. Ghanashev, M. Nagatsu, G. Xu, and H. Sugai, Jpn. J. Appl. Phys. Pt. 136 , 4704 (1997).

93J. Pollak, M. Moisan, and Z. Zakrzewski, Plasma Sources Sci. Technol. 16, 310 (2007).

${ }^{94} \mathrm{~J}$. M. Palomares, E. I. Iordanova, A. Gamero, A. Sola, and J. J. A. M. van der Mullen, J. Phys. D Appl. Phys. 43, 395202 (2010).

${ }^{95}$ B. Debord, R. Jamier, F. Gérôme, O. Leroy, C. Boisse-Laporte, P. Leprince, L. L. Alves, and F. Benabid, Opt. Express 21, 25509 (2013).

${ }^{96}$ B. Debord, L. L. Alves, F. Gérôme, R. Jamier, O. Leroy, C. Boisse-Laporte, P. Leprince, and F. Benabid, Plasma Sources Sci. Technol. 23, 015002 (2014).

${ }^{97}$ C. A. Balanis, Antenna Theory: Analysis and Design, 3rd ed. (Wiley, Hoboken, NJ, 2005), Chap. 9.4, pp. 508-515.

${ }^{98} \mathrm{~K}$. Ono, Jpn. J. Appl. Phys. 20, 1515 (1981).

${ }^{99} \mathrm{H}$. W. Liepmann and A. Roshko, Elements of Gas Dynamics (Wiley, New York, 1957), Chap. 2, pp. 39-61; ibid. Chap. 5, pp. 124-143.

${ }^{100}$ G. P. Sutton and O. Biblarz, Rocket Propulsion Elements, 7th ed. (Wiley, New York, 2001), Chap. 2, pp. 27-44; ibid. Chap. 3, pp. 45-101; ibid. Chap. 19, pp. 660-710.

${ }^{101}$ J. Gregório, S. Parsons, and J. Hopwood, Plasma Sources Sci. Technol. 25, 035018 (2016).

${ }^{102}$ A. R. Striganov and N. S. Sventitskii, Tables of Spectral Lines of Neutral and Ionized Atoms (IFI/Plenum, New York, 1968).
${ }^{103}$ R. W. B. Pearse and A. G. Gaydon, The Identification of Molecular Spectra, 3rd ed. (Chapman \& Hall, London, 1963).

${ }^{104} \mathrm{~K}$. P. Huber and G. Hertzberg, Molecular Spectra and Molecular Structure: IV. Constants of Diatomic Molecules (Van Nostrand Reinhold, New York, 1979).

${ }^{105}$ H. R. Griem, Spectral Line Broadening by Plasmas (Academic, New York, 1974).

${ }^{106}$ Q. Wang, I. Koleva, Y. M. Donnelly, and D. J. Economou, J. Phys. D Appl. Phys. 38, 1690 (2005).

${ }^{107}$ A. Bogaerts and R. Gijbels, Phys. Rev. E 65, 056402 (2002).

${ }^{108}$ T. Kimura and H. Kasugai, J. Appl. Phys. 107, 083308 (2010).

${ }^{109}$ A. T. Hjartarson, E. G. Thorsteinsson, and J. T. Gudmundsson, Plasma Sources Sci. Technol. 19, 065008 (2010).

${ }^{110} \mathrm{M}$. Sode, T. Schwarz-Selinger, and W. Jacob, J. Appl. Phys. 113, 093304 (2013).

${ }^{11}$ M. Sode, T. Schwarz-Selinger, and W. Jacob, J. Appl. Phys. 114, 063302 (2013).

${ }^{112}$ F. Debaly, J. Bretagneyz, M. Jumety, M. Wauteletyx, J. P. Dauchoty, and M. Hecqy, Plasma Sources Sci. Technol. 7, 219 (1998).

${ }^{113}$ J. Henriques, E. Tatarova, V. Guerra, and C. M. Ferreira, J. Appl. Phys. 91, 5622 (2002).

${ }^{114}$ J. Henriques, E. Tatarova, F. M. Dias, and C. M. Ferreira, J. Appl. Phys. 91, 5632 (2002).

${ }^{115}$ J. S. Poirier, P.-M. Bérubé, J. Muñoz, J. Margot, L. Stafford, and M. Chaker, Plasma Sources Sci. Technol. 20, 035016 (2011).

${ }^{116}$ N. Kang, F. Gaboriau, S.-G. Oh, and A. Ricard, Plasma Sources Sci. Technol. 20, 045015 (2011).

${ }^{117}$ D. R. Boris, G. M. Petrov, E. H. Lock, T. B. Petrova, R. F. Fernsler, and S. G. Walton, Plasma Sources Sci. Technol. 22, 065004 (2013).

${ }^{118}$ G. M. Petrov, D. R. Boris, T. B. Petrova, E. H. Lock, R. F. Fernsler, and S. G. Walton, Plasma Sources Sci. Technol. 22, 065005 (2013).

${ }^{119}$ E. H. Lock, T. B. Petrova, G. M. Petrov, D. R. Boris, and S. G. Walton, Phys. Plasmas 23, 043518 (2016).

${ }^{120}$ E. S. Fishburne, J. Chem. Phys. 47, 58 (1967).

${ }^{121}$ D. W. Setser, D. H. Stedman, and J. A. Coxon, J. Chem. Phys. 53, 1044 (1970).

${ }^{122}$ D. Rapp and P. Englander-Golden, J. Chem. Phys. 43, 1464 (1965). 